\title{
ULIRS, an optimal estimation retrieval scheme for carbon monoxide using IASI spectral radiances: sensitivity analysis, error budget and simulations
}

\author{
S. M. Illingworth ${ }^{1}$, J. J. Remedios ${ }^{1}$, H. Boesch ${ }^{1}$, D. P. Moore ${ }^{1}$, H. Sembhi ${ }^{1}$, A. Dudhia ${ }^{2}$, and J. C. Walker ${ }^{2}$ \\ ${ }^{1}$ Earth Observation Science, Department of Physics and Astronomy, University of Leicester, University Road, \\ Leicester, LE1 7RH, UK \\ ${ }^{2}$ Atmospheric, Oceanic and Planetary Physics, Department of Physics, University of Oxford, Parks Road, \\ Oxford, OX1 3PU, UK
}

Received: 2 August 2010 - Published in Atmos. Meas. Tech. Discuss.: 24 August 2010

Revised: 22 January 2011 - Accepted: 2 February 2011 - Published: 11 February 2011

\begin{abstract}
This paper presents a new retrieval scheme for tropospheric carbon monoxide $(\mathrm{CO})$, using measured radiances from the Infrared Atmospheric Sounding Interferometer (IASI) onboard the MetOp-A satellite. The University of Leicester IASI Retrieval Scheme (ULIRS) is an optimal estimation retrieval scheme, which utilises equidistant pressure levels and a floating pressure grid based on topography. It makes use of explicit digital elevation and emissivity information, and incorporates a correction for solar surface reflection in the daytime with a high resolution solar spectrum. The retrieval scheme has been assessed through a formal error analysis, via the simulation of surface effects and by an application to real IASI data over a region in Southern Africa. The ULIRS enables the retrieval of between 1 and 2 pieces of information about the tropospheric $\mathrm{CO}$ vertical profiles, with peaks in the sensitivity at approximately 5 and $12 \mathrm{~km}$. Typical errors for the African region relating to the profiles are found to be $\sim 20 \%$ at 5 and $12 \mathrm{~km}$, and on the total columns to range from 18 to $34 \%$. Finally the performance of the ULIRS is shown for a range of simulated geophysical conditions.
\end{abstract}

\section{Introduction}

Carbon monoxide (CO) in the troposphere acts as a marker or tracer of pollution events on both the regional and global scale, as well as acting as a reference source for incomplete combustion processes. Through its reactions with the hydroxyl radical $\mathrm{OH}$, the concentration of $\mathrm{CO}$ is also related to

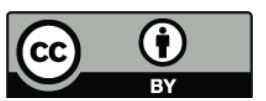

Correspondence to: S. M. Illingworth (smi3@le.ac.uk) the oxidising capacity of the troposphere (Thompson, 1992), and investigations into perturbations of the sources, sinks and net surface fluxes of $\mathrm{CO}$ are therefore of increasing importance.

Our current knowledge of the global CO budget is limited by our understanding of the spatial and temporal variability of the $\mathrm{CO}$ sources and sinks. The incomplete combustion of fossil fuels provides the dominant source of $\mathrm{CO}$ in the northern midlatitudes, whilst the main sources in the tropics are the oxidation of both methane $\left(\mathrm{CH}_{4}\right)$ and biogenic nonmethane hydrocarbons (NMHC), as well as biomass burning (Holloway et al., 2000). The main sink (90 to 95\%) of tropospheric $\mathrm{CO}$ is its reaction with the $\mathrm{OH}$ free radical in the free troposphere (Logan et al., 1981), with the flux of CO out of the troposphere and into the stratosphere accounting for approximately 5\% (Taylor et al., 1996). Due to its relatively short lifetime of 1 to 3 months, $\mathrm{CO}$ exhibits elevated concentrations in the vicinity of its sources; global measurements are therefore vital in the aid of identifying the main source regions of $\mathrm{CO}$ and for the quantification of the source strength.

Whilst ground based and in situ instruments are able to provide accurate measurements of tropospheric concentrations of $\mathrm{CO}$, they are not able to provide global coverage. As such, observations from space are required to allow for fully global measurements of $\mathrm{CO}$ concentrations to be made over a reasonably short time period; the first instrument to do so was the Measurement of Air Pollution from Satellites (MAPS) instrument, which was flown aboard the Space Shuttle four times in the 1980s and 1990s (Reichle Jr. et al., 1999).

Following on from MAPS, infrared instruments such as MOPITT (Measurements Of Pollution In The Troposphere) (Deeter et al., 2003), IMG (Interferometer Monitor for

Published by Copernicus Publications on behalf of the European Geosciences Union. 
Greenhouse Gases) (Kobayashi et al., 1999), AIRS (Atmospheric Infrared Sounder) (McMillan et al., 2005), and TES (Tropospheric Emission Spectrometer) (Rinsland et al., 2006) have successfully exploited high resolution spectroscopic features to increase the vertical information content of profiles and also global coverage. In the past decade SCIAMACHY (SCanning Imaging Absorption SpectroMeter for Atmospheric CHartographY) (Bovensmann et al., 1999; Straume et al., 2005) and more recently MOPITT, have added further sensitivity near the surface through the use of shortwave infrared measurements (Deeter et al., 2009). The IASI (Infrared Atmospheric Sounding Interferometer) is the latest instrument in the infrared suite of tropospheric sounders.

This paper discusses the University of Leicester IASI Retrieval Scheme (ULIRS), which has been developed to determine $\mathrm{CO}$ profile and tropospheric total column amounts under clear sky conditions using IASI measured Top Of Atmosphere (TOA) radiances. Section 2 describes the IASI instrument. A quantitative discussion of factors which affect the retrieval process, and the justification for the selection of parameters used by the ULIRS, is reasoned in Sect. 3, and Sect. 4 outlines the sensitivity of the ULIRS to both the a priori and auxiliary data sets used in the retrieval scheme. Finally, Sect. 5 presents a series of simulations which demonstrate the capability of the ULIRS to retrieve tropospheric CO profiles for a wide range of scenarios, and the conclusions of this work are summarised in Sect. 6.

\section{IASI}

The IASI is a high-resolution Michelson interferometer which was launched in 2007, onboard the European Polar Meteorological Operational Platform (MetOp-A) satellite (Clerbaux et al., 2009), with an Instantaneous Field of View (IFOV) of approximately $12 \mathrm{~km}$ in diameter at nadir. IASI covers the spectral range between 645 to $2760 \mathrm{~cm}^{-1}$, with a spectral sampling of $0.25 \mathrm{~cm}^{-1}$ and a nominal apodised spectral resolution of $0.5 \mathrm{~cm}^{-1}$ (Blumstein et al., 2004). A more detailed description of the IASI instrument is given by e.g., Clerbaux et al. (2009) and Camy-Peyret and Eyre (1998); in this section we briefly discuss why the IASI is a very good instrument for providing detailed information about the global distribution of $\mathrm{CO}$, on both short and long term timescales.

The IASI instrument's spectral range, and low noise in the $4.7 \mu \mathrm{m}$ region of approximately $\pm 2 \mathrm{nW} \mathrm{cm}^{-2} \mathrm{~cm}^{-2} \mathrm{sr}^{-1}$ (see Sect. 3.5.1) mean that it is well qualified to observe the CO spectral band centred on $2140 \mathrm{~cm}^{-1}$. Illingworth et al. (2009) showed the radiometric accuracy of IASI to be better than $0.2 \mathrm{~K}$ at 10 to $12 \mu \mathrm{m}$, and by considering work done by other studies (see e.g., Larar et al., 2010), and acknowledging that the radiometric calibration error between any 2 channels of the IASI instrument is $<0.1 \mathrm{~K}$ (Blumstein et al., 2004), it can be stated that in the $4.7 \mu \mathrm{m}$ region the IASI instrument is radiometrically accurate to $<0.3 \mathrm{~K}$, which is better than the $0.5 \mathrm{~K}$ originally stipulated in the IASI Science Plan (CamyPeyret and Eyre, 1998). Therefore we believe that IASI is of a sufficient accuracy that the radiometric calibration of the measurements is not a substantial source of error.

In order to observe how the atmospheric composition of $\mathrm{CO}$ changes on a daily scale it is necessary to use an instrument which is able to make global measurements at least once a day. The large swath width of the IASI instrument $(2200 \mathrm{~km})$, means that it is able to achieve a twice daily global coverage (99\%), although clouds will greatly reduce the actual daily retrieval coverage from the ideal. As the first of a series of three instruments to be launched every five years, IASI will allow for the monitoring of long-term climatological trends at a very high temporal resolution. For further discussions on the suitability of IASI for observing $\mathrm{CO}$ from space see e.g., Clerbaux et al. (2009); Fortems-Cheiney et al. (2009); George et al. (2009); Turquety et al. (2009)

The IASI data used in this paper are the Level 1C, geolocated and apodised spectra. They are part of the operationally produced version 2.0 data set, obtained from the UMARF archive of IASI data.

\section{ULIRS methodology}

This section describes how the ULIRS retrieves atmospheric CO from IASI measured TOA radiances.

\subsection{Retrieval theory}

\subsubsection{The forward model}

The forward model $\mathbf{F}$ describes the relationship between the measurement $y$ and the state vector $\boldsymbol{x}$, and can be written as:

$y=\mathbf{F}(\boldsymbol{x} b)+\epsilon$.

The ULIRS employs the Reference Forward Model (RFM) as a forward model. The RFM is a line-by-line Radiative Transfer (RT) model, which was developed at the University of Oxford (UK), and can be used to simulate the TOA signal as measured by a spaceborne sensor (Dudhia, 2000). The RFM is based on the GENLN2 RT model (Edwards, 1992), and was designed to provide reference spectral calculations for the Michelson Interferometer for Passive Atmospheric Sounding (MIPAS) a high spectral resolution limbsounding instrument on board the Envisat satellite. The RFM includes a term for the atmospheric emission reflected by the earth's surface, modelling this reflection as specular, and can be operated for any spectral range between $0.001 \mathrm{~cm}^{-1}$ and $2000 \mathrm{~cm}^{-1}(10 \mathrm{~m}$ to $0.5 \mu \mathrm{m})$ at a spectral fine grid sampling of of 0.0005 to $1.0 \mathrm{~cm}^{-1}$, thus making the RFM ideally suited for simulating IASI TOA measured radiances, which have a spectral sampling of $0.25 \mathrm{~cm}^{-1}$ (see Sect. 2). 
The TOA radiation measured by the IASI instrument is composed of two main terms: the longwave radiation emitted by the Earth, and the back-scattered solar radiation. The RFM is able to very accurately simulate the longwave radiation emitted by the Earth, but it has no component to model the back-scattered solar radiation. Ignoring scattering effects, a reasonable assumption in the Thermal InfraRed (TIR) because of the particle size of atmospheric aerosols, the reflected solar radiation, as detected by the IASI instrument, is represented in the ULIRS using the following equation:

$\mathbf{I}(\lambda)=\mathbf{A} \mathbf{I}_{0}(\lambda) \exp \left(-\gamma(\lambda)\left(1 \cos \left(\theta_{\text {sat }}\right)\right)+\left(1 \cos \left(\theta_{\text {sol }}\right)\right)\right)$

where $\mathbf{I}(\lambda)$ is the reflected solar radiation term detected at the TOA by IASI, $\mathbf{A}$ is the surface Albedo, $\mathbf{I}_{0}(\lambda)$ is the solar radiance which is incident on the Earth, $\gamma(\lambda)$ is the optical depth of the atmosphere, $\theta_{\text {sat }}$ is the IASI satellite zenith angle, and $\theta_{\text {sol }}$ is the solar zenith angle. $\mathbf{I}_{0}$ is calculated using the solar irradiance and the Atmospheric Chemistry Experiment (ACE) FTS atlas of the infrared solar spectrum (Hase et al., 2010), $A$ is calculated from the a priori emissivity of the scene (see Sect. 3.4.1), and $\gamma$ is calculated using the RFM.

\subsubsection{The inverse problem}

In order to determine the state vector (true atmospheric state) from the measurement vector (measured radiance), the solution to Eq. (1) needs to be inverted. This problem may be "ill-conditioned", meaning that the inversion needs some form of regularisation. The ULIRS uses an Optimal Estimation Method (OEM), which is described in detail by Rodgers (2000), and which constrains the inversion with a priori information about the variables to be retrieved. This a priori information consists of a mean prior state $\boldsymbol{x}_{\mathrm{a}}$ and an a priori covariance matrix $\mathbf{S}_{\mathrm{a}}$, which represent the best statistical knowledge that we have of the state prior to any measurement being made. The a priori information must come from an independent source, with the choice of a priori used by the ULIRS in this study discussed in detail in Sect. 3.3.

\subsubsection{Characterisation and error analysis}

The averaging kernel matrix $\mathbf{A}$ is a representative of the sensitivity of the retrieved state to the true state:

$\mathbf{A}=\frac{\partial \hat{\boldsymbol{x}}}{\partial \boldsymbol{x}}$

Where $\hat{\boldsymbol{x}}$ is the retrieved state vector. The Degrees Of Freedom for Signal (DOFS) are a measurement of the information content of the retrieval, and are defined as the trace of A. Recent work Ceccherini and Ridolfi (2010) proposed a new method to estimate the Averaging Kernel Matrix (AKM), when using a retrieval scheme that incorporated the Levenberg-Marquardt iterative technique (see
Sect. 3.2.3). This work concluded that the AKM was best represented by the following equation:

$\mathbf{A}=\mathbf{T} \mathbf{K}$.

Where $\mathbf{K}$ is the Jacobian and $\mathbf{T}$ is defined as:

$\mathbf{T}_{i+1}=\mathbf{G}_{i}+\left(\mathbf{I}-\mathbf{G}_{i} \mathbf{K}_{i}-\mathbf{M}_{i} \mathbf{S}_{\mathrm{a}}^{-1}\right) \mathbf{T}_{i}$,

where we have defined:

$$
\begin{aligned}
& \mathbf{M}_{i}=\left(\mathbf{K}_{i}^{T} \mathbf{S}_{\mathrm{y}}^{-1} \mathbf{K}_{i}+(1+\lambda) \mathbf{S}_{\mathrm{a}}^{-1}\right) \\
& \mathbf{G}_{i}=\mathbf{M}_{i} \mathbf{K}_{i}^{T} \mathbf{S}_{\mathrm{y}}^{-1} .
\end{aligned}
$$

Where $\lambda$ is a damping factor (see Sect. 3.2.3), and $\mathbf{T}$ takes into account all of the iterations required by the minimisation process of the OEM, from the initial guess to the solution. Ceccherini and Ridolfi (2010) concluded that this new methodology resulted in the best possible agreement with accurate estimates derived a posteriori, and as such this methodology is adopted by the ULIRS.

The ULIRS assumes a linear approach for the error analysis, outlined by Rodgers (2000), in conjunction with a new methodology proposed by Ceccherini and Ridolfi (2010) for calculating the measurement error covariance matrix $\mathbf{S}_{\mathrm{m}}$, defining it to be given by:

$\mathbf{S}_{\mathrm{m}}=\mathbf{T} \mathbf{S}_{\mathrm{y}} \mathbf{T}^{T}$.

Where $\mathbf{S}_{\mathrm{y}}$ is the noise covariance matrix. The forward model parameter error for each of the trace gases that need to be considered, but are not retrieved (see Sect. 3.2.1) is calculated using the following equation from Rodgers (2000)

$\boldsymbol{\epsilon}_{\mathrm{param}}=\mathbf{G} \mathbf{K}_{b} \mathbf{S}_{b} \mathbf{K}_{b}^{T} \mathbf{G}^{T}$.

Where $b$ is the forward model parameter error.

\subsection{Retrieval setup}

\subsubsection{Choice of spectral window and state vector}

The spectral domain of the IASI instrument includes the (10 ) vibration-rotation band of $\mathrm{CO}$ at $4.7 \mu \mathrm{m}$, with the strongest absorption lines of this band being spread from 2040 to $2190 \mathrm{~cm}^{-1}$. This band also contains other absorbers which act to contaminate the spectra, and ideally a spectral window where these contaminants is minimised should be chosen. Figure 1 represents a simulated IASI radiance spectrum for the 2040 to $2190 \mathrm{~cm}^{-1}$ spectral region, corresponding to tropical atmospheric conditions, together with the individual contributions of the strongest absorbers in this domain: $\mathrm{H}_{2} \mathrm{O}, \mathrm{CO}_{2}, \mathrm{O}_{3}, \mathrm{~N}_{2} \mathrm{O}$, and $\mathrm{CO}$. Water vapour absorbs irregularly throughout the region and its contribution cannot be avoided. The $\mathrm{O}_{3}$ signature extends from 2060 to $2135 \mathrm{~cm}^{-1}$, whilst $\mathrm{N}_{2} \mathrm{O}$ saturates the signal above $2180 \mathrm{~cm}^{-1}$. In order to avoid the interferences due to $\mathrm{O}_{3}$ and $\mathrm{N}_{2} \mathrm{O}$ the spectral region 

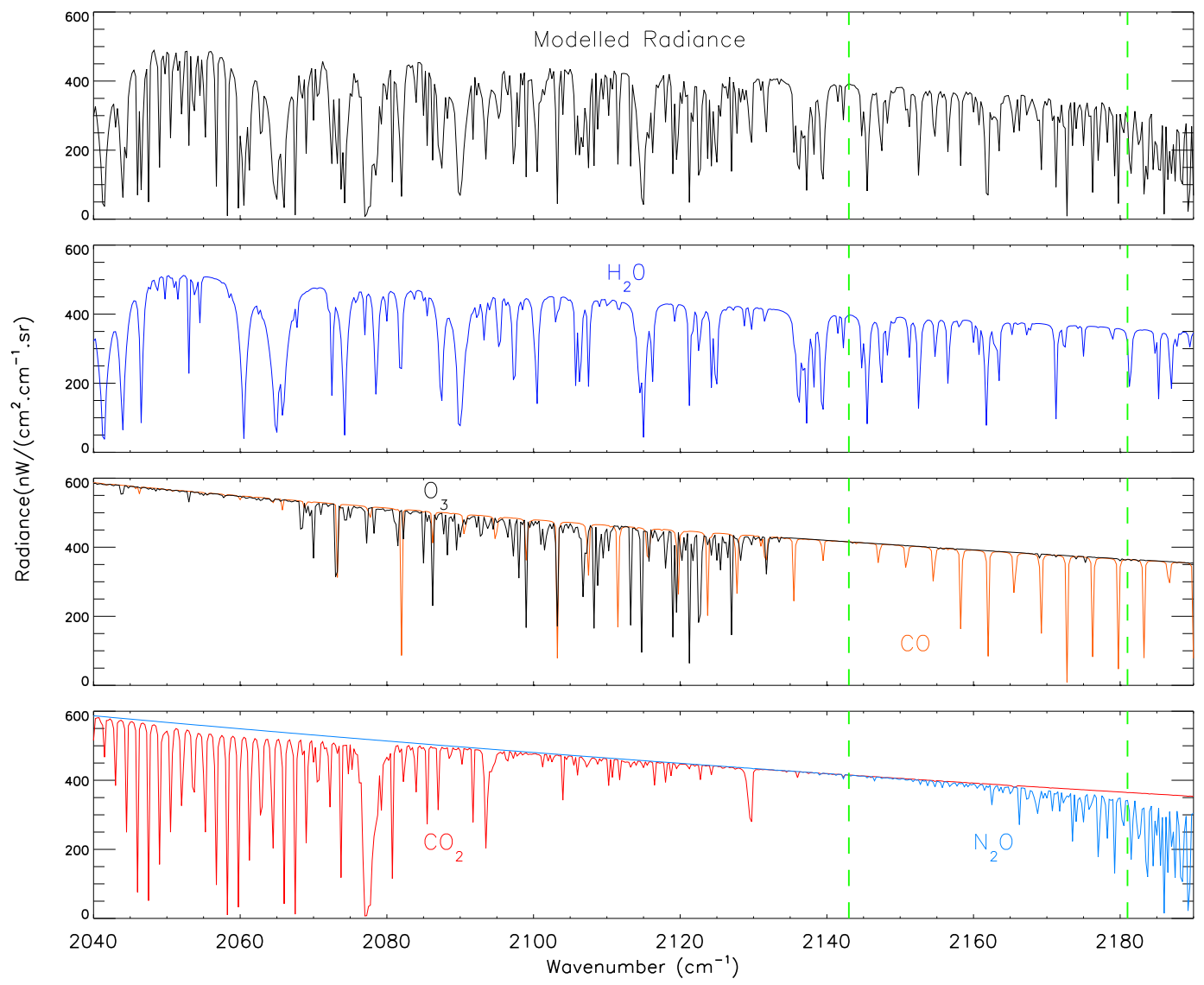

Fig. 1. Simulated IASI radiances for the 2040 to $2190 \mathrm{~cm}^{-1}$ spectral range (top panel). The contributions of the main absorbers in this spectral range are provided in the bottom three panels. The spectral window selected for the CO profile retrieval $\left(2143\right.$ to $\left.2181 \mathrm{~cm}^{-1}\right)$ is indicated by the vertical green lines.

used for the ULIRS CO retrieval is limited to the $\mathrm{R}$ branch of the TIR CO absorption band from 2143 to $2181 \mathrm{~cm}^{-1}$; such a window has also been used to successfully retrieve $\mathrm{CO}$ by other retrieval schemes using spaceborne high-resolution FTIR nadir measurements (see e.g., Barret et al., 2005; Turquety et al., 2009).

As can be seen from Fig. 1, $\mathrm{H}_{2} \mathrm{O}$ and $\mathrm{CO}$ are the dominant absorbers in this spectral region, and delineating between the effect of the two of them is a non-trivial task. The errors that would otherwise be introduced to the retrieved $\mathrm{CO}$ profiles mean that water vapour is included in the state vector to give a more accurate retrieval. The water vapour that is retrieved is a specific humidity, and it should also be noted that the state vector is in VMR space, for both the CO and the water vapour. For a similar reason the temperature profile is also retrieved, hence the state vector $\boldsymbol{x}$ retrieved by the ULIRS comprises of tropospheric $\mathrm{CO}, \mathrm{H}_{2} \mathrm{O}$ and temperature profiles, as well as a surface temperature term.

\subsubsection{Pressure levels}

The choice of the pressure levels in the retrieval grid is an important one, as they will determine to some extent the sensitivity of $\mathbf{K}$ and $\mathbf{A}$ to different parts of the atmosphere. If a retrieval grid with levels equidistant in altitude (and which therefore had different "masses" of air associated with them) were chosen then this characteristic would produce results that were dependent upon the retrieval grid itself, and might therefore make a direct physical interpretation of $\mathbf{K}$ more difficult. The apparent artifacts in the Volume Mixing Ratio (VMR)-based values for $\mathbf{K}$, caused by the nonuniform spacing of retrieval grid pressure levels, would also lead to the calculation of VMR-based A that were proportionally larger for levels in the true profile associated with thicker layers, and smaller for levels associated with thinner layers; this was also found to be the case by Deeter et al. (2007) who, in the $\mathrm{V} 3$ product of their retrieval algorithm, used a retrieval grid with layers that were non-equidistant in pressure to observe $\mathrm{CO}$ using the MOPITT instrument. Figure 2 illustrates the differences in $\mathbf{K}$ and $\mathbf{A}$ when using a 30 level retrieval grid, which is equidistant in either pressure or altitude. It 

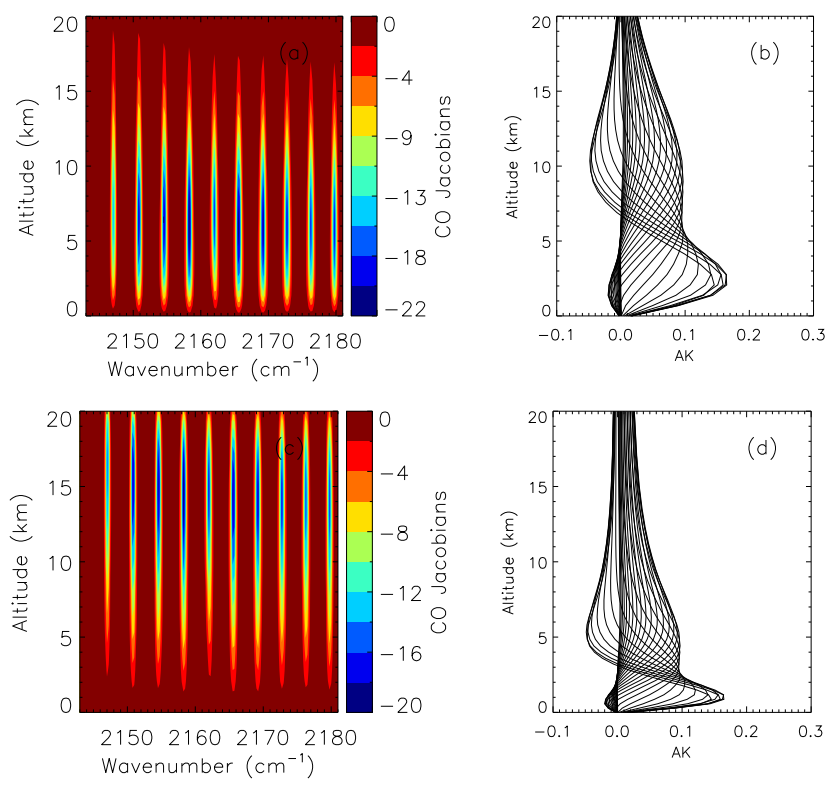

Fig. 2. K and A calculated using a 30 level retrieval grid, and which is equidistant in either altitude ( 0 to $20 \mathrm{~km}$ ) or pressure (1000 to $50 \mathrm{hPa}$ ). (a) $\mathbf{K}$ for a retrieval grid that is equidistant in altitude. (b) $\mathbf{A}$ for a retrieval grid that is equidistant in altitude. (c) $\mathbf{K}$ for a retrieval grid that is equidistant in pressure. (d) A for a retrieval grid that is equidistant in pressure. The units of the Jacobians are radiances per VMR.

should be noted that the issue of choosing equidistant pressure levels for the grid selection are relevant to the visualisation and interpretation of $\mathbf{K}$ and $\mathbf{A}$, but not to their validity. Using an irregular grid by itself is not a source of retrieval error.

The retrieval grid was chosen to consist of a fixed number of levels which varied between the surface pressure and $50 \mathrm{hPa}$ (approximately $20 \mathrm{~km}$ ). This means that the minimum pressure will always be $50 \mathrm{hPa}$, but the surface pressure will depend upon the surface elevation of the IASI IFOV (see Sect. 3.4.2). By using this particular methodology (rather than choosing a fixed set of pressure levels, as is done in the case of the MOPITT operational CO product), the problem of having a retrieval pressure level which is greater than that of the surface pressure, as would be the case over (for example) a mountain, does not arise. It should also be noted that the RFM produces Jacobians for a triangular perturbation centred on the pressure level that ends at the adjacent pressure levels, but the retrieved profile itself is on a grid which corresponds to the pressure levels.

Figure 3 illustrates the effect that the number of levels in a retrieval grid has on the RFM's ability to accurately simulate TOA radiances. By choosing 40 levels, spaced equidistantly in pressure, it was found that the RFM was able to simulate any spectral features that would be observed by the IASI instrument in the selected spectral window, given the spectral sampling and resolution of the instrument. By choosing to
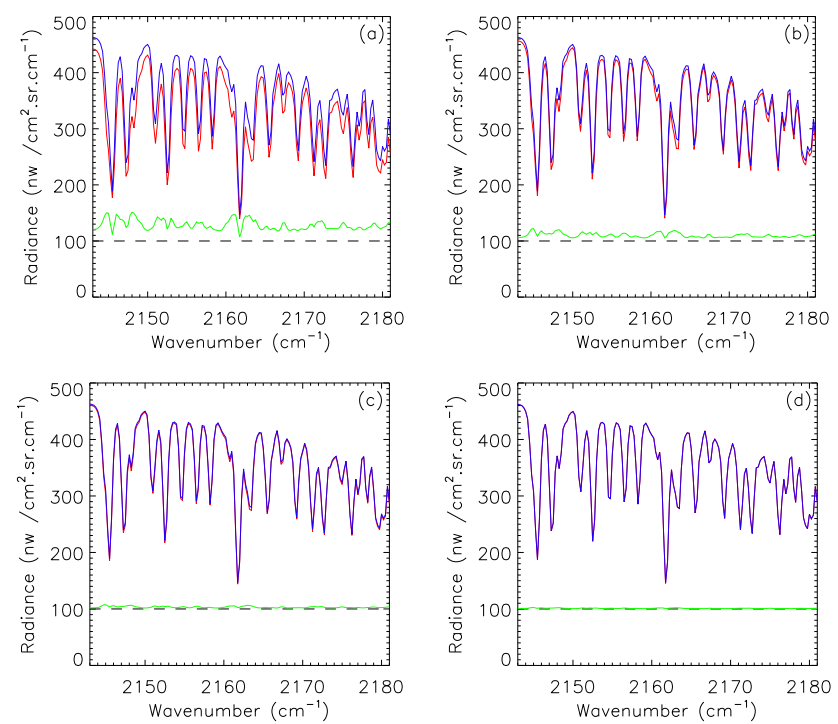

Fig. 3. The effect that the number of retrieval levels has on the RFM's accuracy in generating spectra at: (a) 5 levels (red), 40 levels (blue), and the residual + 100 (green); (b) 10 levels (red), 40 levels (blue), and the residual + 100 (green); (c) 20 levels (red), 40 levels (blue), and the residual + 100 (green); (d) 30 levels (red), 40 levels (blue), and the residual +100 (green). In the cases of (a)(c) the residual is higher than the noise in this spectral region $\left(2 \mathrm{nW} \mathrm{cm}^{-2} \mathrm{~cm}^{-2} \mathrm{sr}^{-1}\right)$.

perform the retrieval over 30 levels instead of 40 the processing time of the RFM is decreased by a factor of 1.5 , without any significant degradation in the accuracy of the simulation (see Fig. 3). To summarise, the ULIRS incorporates a retrieval grid with 30 levels that are equidistant in pressure, and which ranges from the surface pressure to $50 \mathrm{hPa}$.

\subsubsection{Iteration and convergence}

The ULIRS uses a Levenberg-Marquardt iterative technique, which makes use of a damping factor $\lambda$, chosen so as to minimise the cost function at each step of the iteration (Rodgers, 2000). After each iteration the cost function is calculated, and compared to the cost function of the previous iteration, if there has been an increase in the cost function then the damping factor is increased by a factor of 8 , and if there has been a reduction in the cost function, then the damping factor is reduced by a factor of 4 . These values, along with an initial damping factor of 0.1 where chosen based on the work done by Ceccherini and Ridolfi (2010).

Convergence analysis is needed to establish the correct criterion for stopping the iterations for each retrieval. In order to make sure that an accurate convergence is reached, the iterations are stopped when one of the following two criteria are reached: (i) the number of iterations exceeds 10; (ii) the relative variation of the cost function is less than 0.01 . These two criteria have been chosen as they are consistent with the 
literature (see e.g., Ceccherini and Ridolfi, 2010), with the ULIRS typically reaching convergence in 3 to 4 iterations.

Once an iteration has converged, it is necessary to test if this retrieved spectra is a sensible representation of the real spectra, as measured by the IASI instrument. A suitable test for a correct convergence is to calculate a value for the normalised cost function (Rodgers, 2000). If the normalised cost function is approximately unity then the retrieved spectra can be assumed to be a good representation of the real spectra. The ULIRS calculates a value of the normalised cost function for each retrieved scene, therefore giving an indication of the reliability of the retrieval.

\subsection{A priori data}

\subsubsection{Climatologies}

Aside from $\mathrm{CO}$, the principal absorbing atmospheric gases in the TIR $\mathrm{CO}$ absorption band are $\mathrm{H}_{2} \mathrm{O}, \mathrm{CO}_{2}, \mathrm{~N}_{2} \mathrm{O}$, and $\mathrm{O}_{3}$ (see Fig. 1). In order to accurately simulate TOA radiances in this region, an accurate representation of the climatology, i.e. the atmospheric concentrations of the relevant gases is required, with water vapour considered separately (see Sect. 3.3.2). The ULIRS makes use of a set of reference atmospheres, or climatologies, that were designed by Remedios et al. (2007) for use in IR sounding. Five atmospheres corresponding to tropical, mid-latitude day/night and polar summer/winter atmospheric conditions are available, with these profiles describing the concentrations of 30 atmospheric species, including $\mathrm{CO}_{2}, \mathrm{~N}_{2} \mathrm{O}$, and $\mathrm{O}_{3}$ between the surface and a height of $120 \mathrm{~km}$, with a vertical step size of $1 \mathrm{~km}$. Continua contributions from $\mathrm{N}_{2}, \mathrm{CO}_{2}$ and $\mathrm{H}_{2} \mathrm{O}$ were also included in the forward model.

\subsubsection{Temperature and water vapour profiles}

The tropospheric temperature and water vapour are so highly variable, on such relatively short time and spatial scales, that they must be represented by a more accurate a priori data set than those given by the static reference atmospheres. The a priori tropospheric temperature and water vapour profiles used in the ULIRS algorithm are taken from the European Centre for Medium-Range Weather Forecasts (ECMWF) operational data set, courtesy of the British Atmospheric Data Centre (BADC). This data set is on a $1.125^{\circ} \times 1.125^{\circ}$ grid with 91 pressure levels, and a 6 hourly time resolution.

The ECMWF a priori tropospheric temperature and water vapour profiles associated with each retrieval scene is calculated by first finding the ECMWF data set which is closest in time to when the IASI measurement was made, the four ECMWF grid points that encompass each geolocated IASI pixel are then located. The profiles at these grid points are then linearly interpolated onto the same pressure grid as that used by the ULIRS (see Sect. 3.2.2), after which a spatial

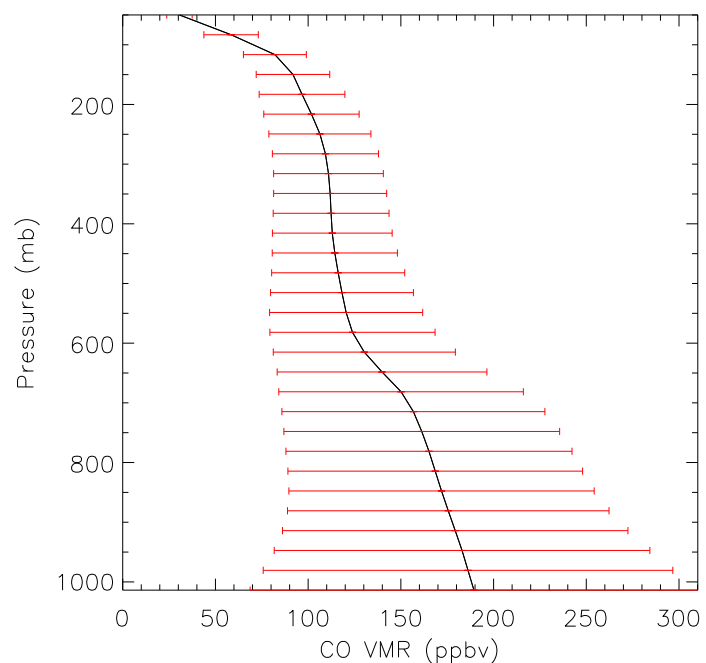

Fig. 4. CO a priori profile used by the ULIRS. The red error bars represent the diagonal elements of the a priori covariance matrix as calculated by determining the covariance between the different TOMCAT CO profiles that were used to construct the a priori profile.

bilinear interpolation is then performed, resulting in a set of a priori tropospheric temperature and water vapour profiles.

\subsubsection{CO profile}

In order to ensure that any spatial or temporal features observed in the retrieved CO product are not symptomatic of features in the a priori, the ULIRS employs a constant a priori CO profile. This profile is constructed using the Toulouse Off-line Model of Chemistry And Transport (TOMCAT) Chemical Transport Model (CTM) (Chipperfield, 2006), run over an entire year for a specified location. The TOMCAT CO emissions are climatological emissions based on the IPCC (Intergovernmental Panel on Climate Change) third assessment report. For the African region which is considered in this paper, the TOMCAT model was run for one year (2004) over a grid box bounded longitudinally from -20 to $50^{\circ} \mathrm{E}$, and latitudinally from -30 to $30^{\circ} \mathrm{N}$, and so as to choose an priori most appropriate to retrievals over land, only profiles where the surface concentration of $\mathrm{CO}$ was greater than $100 \mathrm{ppbv}$ were considered. Once this selection criteria had been established there were approximately 8000 TOMCAT profiles, from which a mean a priori profile was calculated. The a priori profile for tropospheric $\mathrm{CO}$ that was used by the ULIRS in this study is shown in Fig. 4.

Whilst this paper deals with investigating the sensitivity and accuracy of the retrieval over a localised region, in this case Africa, the ULIRS could easily be applied to a global dataset, providing that the a priori and surface properties were constructed accordingly. Were the ULIRS to be used for a truly global retrieval a careful consideration of the choice of a priori for the $\mathrm{CO}$ atmospheric profile would be 
necessary. The use of a single global a priori would ensure that any features in the retrieval could not be traced back to features in the a priori, however at levels where the weighting functions exhibit low sensitivity, the use of a single global profile can result in large systematic differences between the "true" CO concentration and the retrieved values. As this paper deals with optimising the ULIRS over a localised region this issue is not dealt with here; for a more detailed discussion of the relative strengths and weaknesses of a global vs. a spatially dependant a priori please refer to Deeter et al. (2010).

\subsubsection{A priori covariance matrix}

The a priori covariance matrix $\mathbf{S}_{\mathrm{a}}$ determines the uncertainty in the a priori information used in the retrieval. Apart from surface temperature, each of the retrieved parameters has a $n \times n$ covariance matrix associated with it, where $n$ is the number of retrieval levels (30), and which in the case of the ULIRS have been deemed to be independent from one another, i.e. an uncertainty in one retrieved parameter has no direct effect on the uncertainty of any of the other retrieved parameters.

Similarly to the selection of the a priori profile of $\mathrm{CO}$, the choice of $\mathbf{S}_{\mathrm{a}}$ for $\mathrm{CO}$ has a direct effect on the retrieved products, and for this reason it was decided that the $\mathbf{S}_{\mathrm{a}}$ used to represent $\mathrm{CO}$ should remain fixed. In the construction of the $\mathrm{CO}$ a priori profile (see Sect. 3.3.3), the covariance of the atmospheric $\mathrm{CO}$ between each of the retrieval pressure levels of the ULIRS was also calculated from the TOMCAT modelled values, and these values were used to construct the $\mathrm{CO}$ a priori covariance matrix, as shown in Fig. 5.

The square root of the diagonal elements $\mathbf{S}_{\mathrm{a}}$ for the water vapour are set to $10 \%$ of the ECMWF water vapour profile, whilst for the temperature the diagonal elements are set to $1 \%$ of the ECMWF temperature profile. The off-diagonal elements of the water vapour and temperature sections of the a priori covariance matrix are calculated using the GaussMarkov equation:

$\mathbf{S}_{i j}=\sqrt{\mathbf{S}_{i i} \mathbf{S}_{j j}} \exp \left(\frac{-\left(z_{i}-z_{j}\right)^{2}}{z_{\mathrm{s}}^{2}}\right)$

where $z_{i}$ and $z_{j}$ are the altitudes of the $i$-th and $j$-th elements of the profile, and $z_{\mathrm{s}}$ is a "smoothing length". A smoothing length of $3 \mathrm{~km}$ was chosen for both the water vapour and the temperature. The uncertainty in the surface temperature is set to $5 \mathrm{~K}$, resulting in a surface temperature variance of $25 \mathrm{~K}^{2}$ being used.

\subsection{Auxiliary data}

\subsubsection{Emissivity}

The parameters of surface emissivity and surface temperature play an important role in determining the TOA radiances

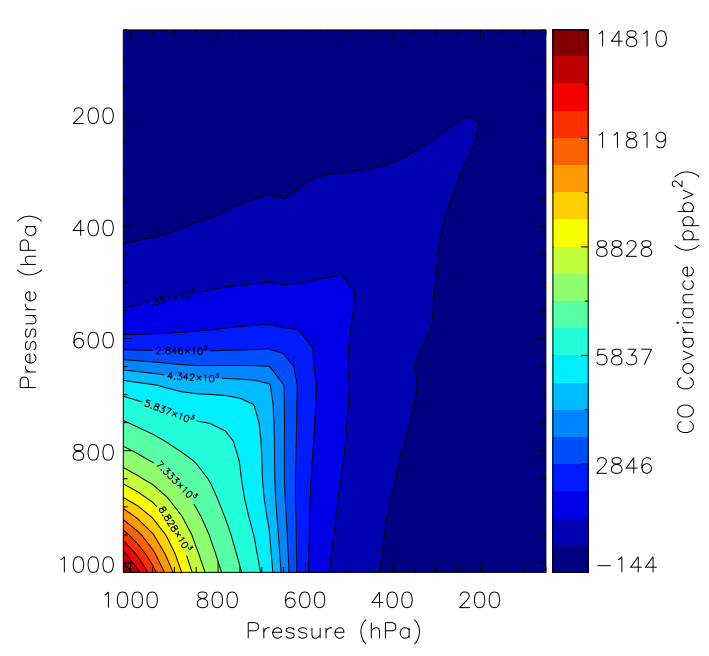

Fig. 5. The CO apriori covariance used by the ULIRS.

that are detected by the IASI instrument, hence it is important that they are accurately represented in the retrieval scheme, and ideally both should be retrieved in addition to the tropospheric CO profiles. However, the separation of the surface emissivity and the surface temperature in the chosen spectral window is not possible because of the nonlinearity of the relationship between radiance and surface temperature. The ULIRS includes a surface temperature term as part of its state vector (see Sect. 3.2.1) and so it is important that each retrieval uses an emissivity for the IFOV that is as representative of the true emissivity of that scene as is possible. As emissivity is a function of both land type and wavenumber, hence both of these must be factored into any auxiliary dataset that is used to represent the surface emissivity.

The Moderate Resolution Imaging Spectroradiometer (MODIS) instrument was designed to provide improved monitoring for land, ocean, and atmosphere research; it was launched by the National Aeronautics and Space Administration (NASA) in 1999 on board the Terra (EOS AM) Satellite, and in 2002 on board the Aqua (EOS PM) satellite (Justice et al., 1998). Seemann et al. (2008) have developed a global database of infrared land surface emissivity, derived using input from the MODIS operational land surface emissivity product (MOD11), and constructed using a baseline fit method developed from laboratory measurements of surface emissivity. This University of Wisconsin (UW) Baseline Fit Emissivity database has a spatial resolution of $0.05^{\circ}$; a monthly temporal resolution; and a spectral resolution of better than $5 \mathrm{~cm}^{-1}$, and has been shown by Seemann et al. (2008) to improve the validity of retrievals, in comparison to those made with a typical assumption of constant emissivity. The ULIRS calculates the surface emissivity for each IFOV by using the UW database to find the mean surface emissivity, and this methodology also enables each IFOV to be flagged as being either over sea, or land, or both. 


\subsubsection{Surface elevation}

In order to ascertain the correct surface pressure of each IFOV, information about the surface elevation is needed. GTOPO30 is a global Digital Elevation Model (DEM) developed by the United States Geological Survey (USGS), with elevations in GTOPO30 regularly spaced at 30" (approximately $1 \mathrm{~km}$ ). When calculating the surface elevation of the IASI IFOV, the ULIRS calculates the surface elevation at the exact (to within $30^{\prime \prime}$ ) geolocation given by the IASI level $1 \mathrm{C}$ data, with the topographic standard deviation within each IFOV also being recorded, so as to give an indication of the homogeneity of the scene.

The initial surface pressure for each IFOV is obtained from the ECMWF pressure profiles, which have been calculated for each scene in a manner identical to that of the a priori temperature and water vapour profiles (see Sect. 3.3.2). This surface pressure corresponds to a geopotential height that is also part of the ECMWF product, and which is then converted to a geometric surface elevation, before being compared to that given by the USGS DEM, and interpolated accordingly. This surface elevation is then used, along with the equation of hydrostatic equilibrium and a latitudinally and vertically dependent gravitational acceleration, to compute the associated height grid used by the ULIRS.

\subsection{Pre-processing}

The ULIRS retrieves tropospheric CO profiles from IASI level $1 \mathrm{C}$ radiances. These level $1 \mathrm{C}$ data products represent geolocated and calibrated IASI spectra, which are sampled onto a spectral grid and then apodised. As part of the data product a quality flag is associated with the level $1 \mathrm{C}$ spectra for each IASI pixel (Camy-Peyret and Eyre, 1998), and this is used to filter the data before the level $1 \mathrm{C}$ radiances are processed by the ULIRS.

\subsubsection{Instrument noise}

The noise of the IASI instrument is a random measurement effect, which must be taken into account when the retrieval by the ULIRS is performed. This random component is represented in the retrieval process by the noise covariance matrix $\mathbf{S}_{\mathrm{y}}$, which is calculated depending upon the noise $\epsilon$ of the IASI instrument, and which has a standard deviation equal to the inverse of the Signal-to-Noise Ratio (SNR). A simplification of $\mathbf{S}_{\mathrm{y}}$ would be to assume that the errors in the different channels are uncorrelated and uniform, resulting in $\mathbf{S}_{\mathrm{y}}$ being a $m \times m$ diagonal matrix, where $m$ (the measurement vector) is the number of measurements, with the diagonal elements corresponding to the expected radiometric noise in the spectral region used, which in the case of the TIR absorption band of CO $\left(2040\right.$ to $\left.2190 \mathrm{~cm}^{-1}\right)$ is approximately $\pm 2 \mathrm{nW} \mathrm{cm}^{-2} \mathrm{~cm}^{-2} \mathrm{sr}^{-1}$. Whilst this simplification has been used successfully by other studies (see e.g., Turquety et al.,

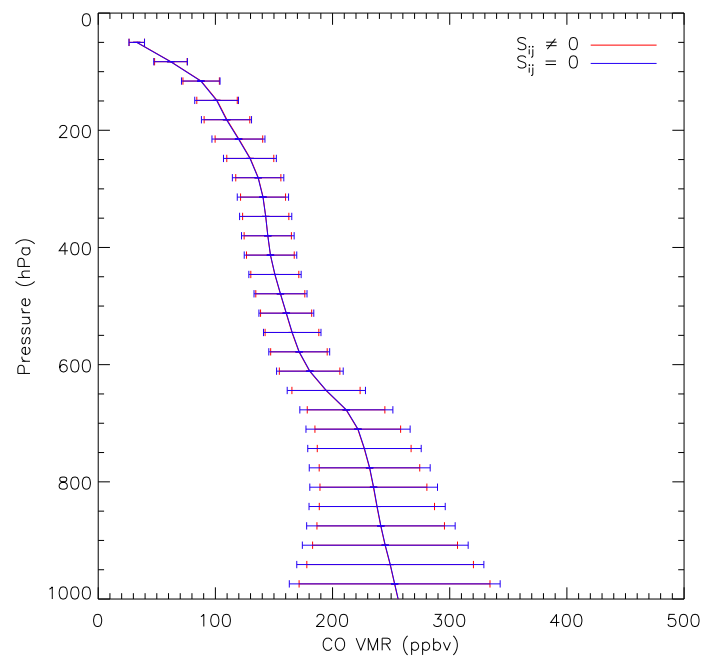

Fig. 6. The effect that the inclusion of a $\mathbf{S}_{\mathbf{y}}$ with non diagonal elements $\left(S_{i j} \neq 0\right)$, in comparison to a purely diagonal one $\left(S_{i j}=0\right)$, has on the retrieved $\mathrm{CO}$ product. These retrievals were performed on radiances which were simulated under daytime mid-latitudinal atmospheric conditions, with a surface emissivity of 0.84 (representative of a desertified region), and a surface elevation of $0 \mathrm{~m}$.

2009), it is not an approach that is used in this work, as by incorporating non-diagonal elements into $\mathbf{S}_{\mathrm{y}}$ for the specified spectral region, we are able to account for the effects of the apodisation. $\mathbf{S}_{\mathrm{y}}$ is constructed using the noise covariance matrix that is supplied as part of the IASI level 1C radiances, with apodisation meaning that the noise in each channel has an non-negligible effect on the five channels surrounding it. However, as can be seen from Fig. 6, the impact of using a non-diagonal $\mathbf{S}_{\mathrm{y}}$ in comparison to a pure diagonal one, is negligible for the retrieval scenarios discussed her.

\subsubsection{Cloud detection algorithm}

The ULIRS has been developed to be optimal in cloud-free scenes, and as such part of the pre-processing of the IASI level $1 \mathrm{C}$ spectra includes a cloud detection algorithm, so that the retrieval does not process any cloudy scenes. No single cloud detection method is able to detect clouds in all situations, and so the cloud detection algorithm used by the ULIRS considers two different cloud detection methods, and uses them concurrently.

The first cloud-detection method that is applied is a simple threshold test, which compares IASI measured Brightness Temperatures (BTs) to the Earth's skin temperature, as outlined by Hadji-Lazaro et al. (2001). The BTs for the IASI spectra are computed at $2133.25,2143$ and $2150 \mathrm{~cm}^{-1}$ (these are slightly modified values from the $2133.28,2143$ and $2150.11 \mathrm{~cm}^{-1}$ values used by Hadji-Lazaro et al., 2001, as they have been rounded to the nearest $0.25 \mathrm{~cm}^{-1}$ to account for the spectral sampling of the IASI instrument), assuming an emissivity of 0.9788 over water, and 0.9677 over land (for 

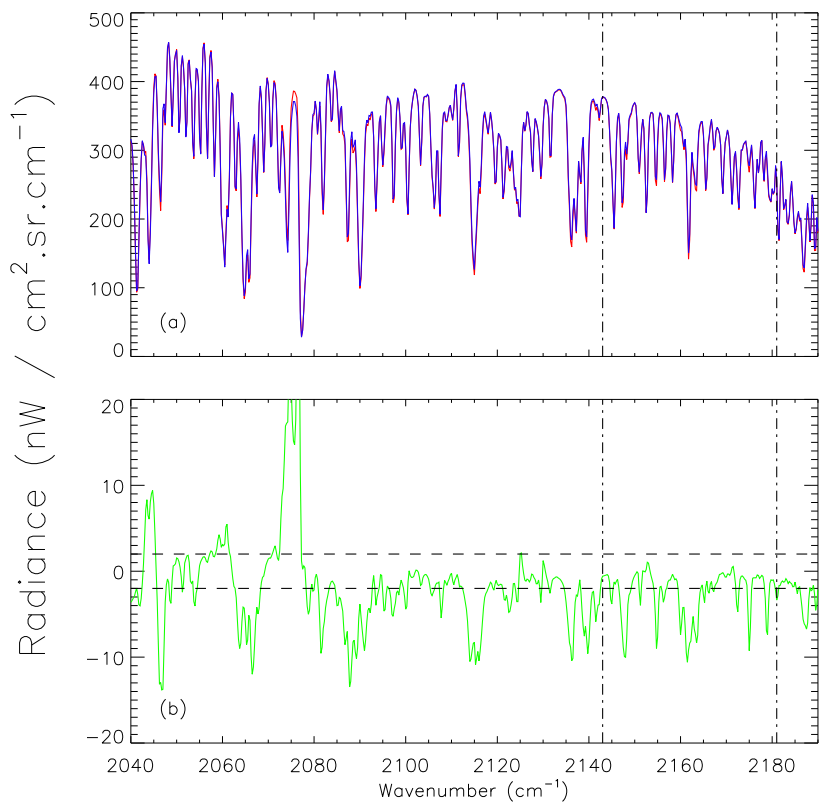

Fig. 7. (a) Synthetic spectra generated using HITRAN 1994 (red line) and 2008 (blue line) spectroscopic data; (b) substantial differences occur between the two spectra, the IASI noise in this spectral window is indicated by the dashed lines. The dashed vertical lines indicate the limits of the fitting interval.

those IASI pixels which lay over both land and water, an emissivity of 0.9677 was used). These BTs are then compared to the ECMWF skin temperature computed for that pixel, and if the difference between any of these BTs and the ECMWF skin temperature exceeds a certain threshold, $8 \mathrm{~K}$ over the sea and $15.3 \mathrm{~K}$ over the land, then the pixel is flagged as being cloudy.

The second cloud detection method that is applied to the data set is a 8 to $11 \mu \mathrm{m}$ delta BT threshold test, which has been adapted from the trispectral brightness temperature method developed by Strabala et al. (1994). Based on this study, wavelength intervals of 8.3 to $8.4 \mu \mathrm{m}$ and 11 to $11.25 \mu \mathrm{m}$ were used, and if the 8 to $11 \mu \mathrm{m}$ delta BTs are less than $0.4 \mathrm{~K}$ then the pixel is flagged as being potentially cloud-free. If both cloud filtering algorithms flag a pixel as being cloud-free then the ULIRS classifies it as such.

\section{Sensitivity analysis}

\subsection{Sensitivity of the RFM}

As discussed in Sect. 3.1.1, the Oxford RFM is used by the ULIRS to model the forward function. We have investigated the use of the RFM to simulate IASI spectra in detail, and a summary of the optimisation of the RFM for use by the ULIRS is now discussed.
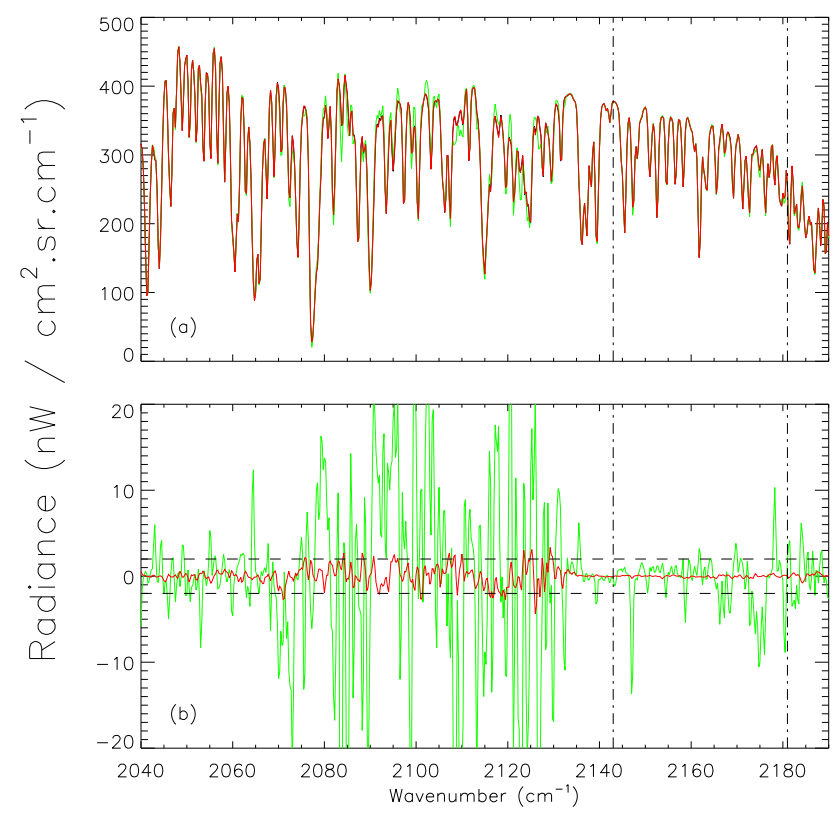

Fig. 8. (a) Synthetic spectra generated using an RFM spectral fine-grid of $0.0005 \mathrm{~cm}^{-1}$ (black), $0.01 \mathrm{~cm}^{-1}$ (red), and $0.1 \mathrm{~cm}^{-1}$ (green); (b) the residual difference between the $0.0005 \mathrm{~cm}^{-1}$ and $0.01 \mathrm{~cm}^{-1}$ (red), and between the $0.0005 \mathrm{~cm}^{-1}$ and $0.1 \mathrm{~cm}^{-1}$ (green) spectral fine-grids. The differences between the $0.0005 \mathrm{~cm}^{-1}$ and the $0.1 \mathrm{~cm}^{-1}$ spectral fine-grids are significant (i.e. larger than the noise of the IASI instrument, which in this spectral window is equal to $2 \mathrm{nW} \mathrm{cm}^{-2} \mathrm{~cm}^{-2} \mathrm{sr}^{-1}$, and which is indicated by the dashed lines), but this is not the case between the $0.0005 \mathrm{~cm}^{-1}$ and the $0.01 \mathrm{~cm}^{-1}$ spectral fine-grids. The dashed vertical lines indicate the limits of the fitting interval. It was decided that the RFM should be performed using a spectral fine-grid of $0.01 \mathrm{~cm}^{-1}$, resulting in simulations that represented the most efficient balance between accuracy and computational processing time.

As the RFM generates synthetic spectra by using spectral line parameters to derive the absorption features of a given trace gas, parameters such as the line position, absorption strength and broadening coefficients need to be quantified very accurately, in order to avoid serious errors in the modelled spectra (see, e.g., Fig. 7). To ensure that simulated spectra are as realistic as possible the latest version of the HIgh-resolution TRANsmission (HITRAN) spectroscopic data base (Rothman et al., 2009) has been implemented by the ULIRS. The spectral fine-grid on which the RFM is run is also a key parameter, and a series of sensitivity tests (see Fig. 8) which aimed to determine the most economical and accurate spectral fine-grid on which to run the RFM, in relation to the retrieval of $\mathrm{CO}$, were performed, resulting in a spectral fine-grid of $0.01 \mathrm{~cm}^{-1}$ being used by the ULIRS.

The RFM was originally designed for retrievals of atmospheric products using MIPAS measured radiances, and as such has a full limb viewing capability, however it can also be run in "nadir" mode, in which case a plane-parallel (PP) 

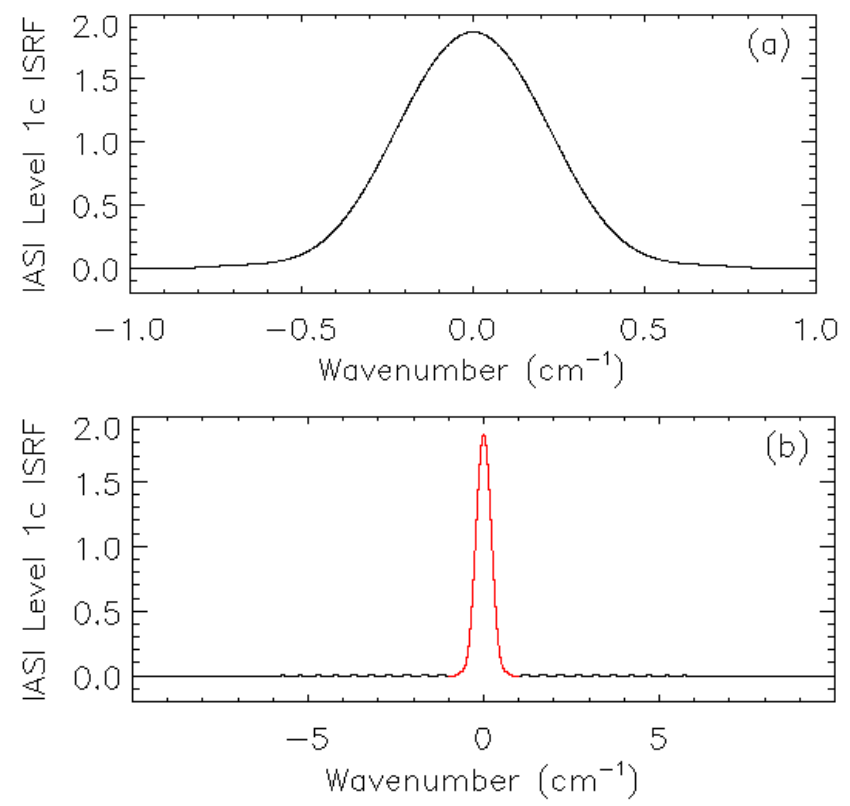

Fig. 9. (a) The modified Instrument Spectral Response Function (ISRF). (b) The ISRF for the IASI instrument, as provided by the EPS (black), and the modified ISRF (red).

approximation is assumed. We have examined the impact of neglecting the curvature of the Earth, and found that the PP method is only recommended for small satellite zenith angles up to approximately $18^{\circ}$, and that at higher viewing angles, the RFM nadir mode should be avoided, instead dealing explicitly with the curvature of the Earth in the radiative transfer calculations. As such the ULIRS uses the limb viewing capability of the RFM, configured so that the line-of-sight intersects the Earth's surface appropriately.

The Effective Field Of View (EFOV) of the IASI instrument is the useful field of view at each scan position, with each EFOV consisting of a $2 \times 2$ matrix of IFOVs. Each IFOV has a diameter of $14.65 \mathrm{mrad}$, which corresponds to a ground resolution of a circle with $12 \mathrm{~km}$ diameter at nadir and $20 \mathrm{~km}$ at the edge of the scan line, along the track. These diameters have been calculated using the satellite zenith angles, assuming a constant satellite altitude of $819 \mathrm{~km}$ above the Earth's surface, and an IFOV of $14.65 \mathrm{mrad}$. We also found that modelling the IASI field-of-view as an infinitesimal beam for the purposes of the forward model is a very good approximation in the TIR CO absorption region, and that in this region any errors introduced by making this approximation remain below the noise level, for all satellite zenith angles.

The RFM can incorporate the effect of the instrument response by specifying a file which accurately describes the Instrument Line Shape (ILS), and onto which the simulated spectra can be convolved, thereby ensuring that the simulated TOA radiances are characteristic of the instrument; the ILS for the IASI instrument is shown in Fig. 9, and it can be seen
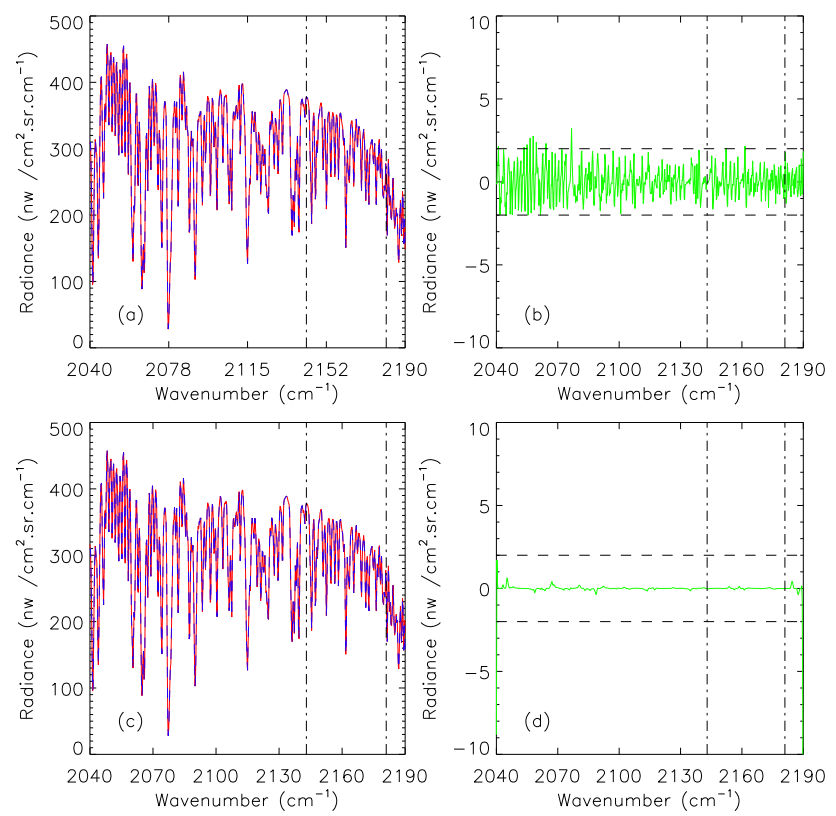

Fig. 10. (a) Synthetic spectra generated by applying the full $10 \mathrm{~cm}^{-1}$ wide ILS function (blue), and truncated $1 \mathrm{~cm}^{-1}$ wide ILS function (red); (b) the residual difference between the $10 \mathrm{~cm}^{-1}$ wide ILS functions, and IASI noise in this spectral window (dashed black line). (c) Synthetic spectra generated by applying the truncated $1 \mathrm{~cm}^{-1}$ wide ILS function both during the RFM calculations (red) and afterwards (blue); (d) the residual difference, and IASI noise in this spectral window (dashed black line). The dashed vertical lines indicate the limits of the fitting interval.

to extend over a wide wavenumber range. Figure 10 shows that the application of a truncated $1 \mathrm{~cm}^{-1}$ wide apodised IASI ILS (see Fig. 9), had a negligible effect in comparison to applying the full ILS, and in doing so the RFM calculations was found to be more computationally efficient, thus this methodology was adopted for use by the ULIRS. Figure 10 also shows that the difference between applying the ILS during the RFM simulation and afterwards is non-negligible at the edges of the spectral window. It should also be noted that when the ILS convolution in the RFM is performed it reverts to a very fine mesh calculation of $0.0005 \mathrm{~cm}^{-1}$

\subsection{Information content and error analysis}

An error analysis, and characterisation of the retrievals, using the methodology outlined in Sect. 3.1.3 is now discussed.

\subsubsection{DOFS}

Two spectra corresponding to a low $(\mathrm{DOFS}=1.21)$ and a high (DOFS $=1.91$ ) information content have been selected for a detailed characterisation. They correspond to simulated retrievals over the Arctic Ocean and the Western Namibian mountain range, for the nighttime and daytime, respectively; Fig. 11 plots the averaging kernels for each of these 

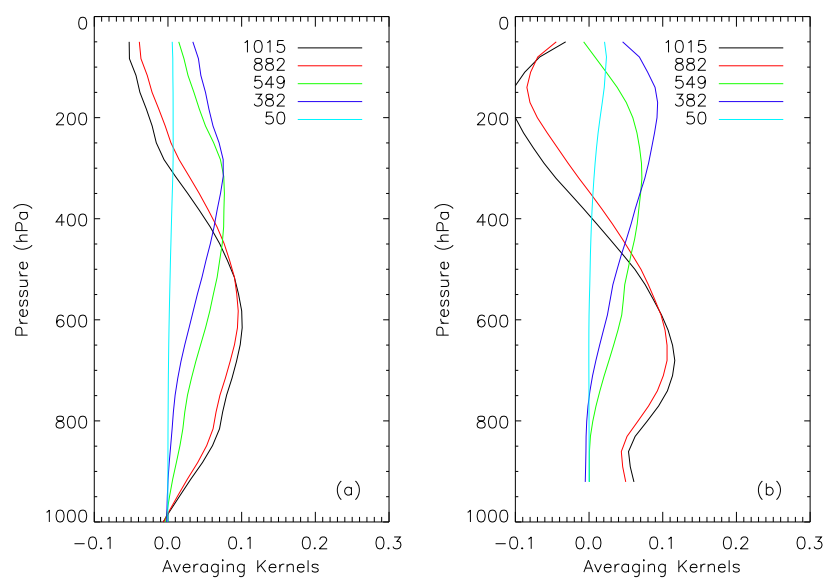

Fig. 11. ULIRS CO averaging kernels for two selected pixels: (a) Arctic Ocean $\left(75.21^{\circ} \mathrm{N}, 115.97^{\circ} \mathrm{E}, 1.21 \mathrm{DOFS}\right)$ and (b) Namibian Mountains $\left(17.67^{\circ} \mathrm{S}, 12.29^{\circ} \mathrm{E}, 1.91 \mathrm{DOFS}\right)$.

two scenes. In the case of the Arctic Ocean, the measurement only allows the retrieval of a single piece of information about the $\mathrm{CO}$ vertical distribution, covering the middleupper troposphere at approximately $500 \mathrm{hPa}$, whereas over the Namibian mountains it is almost possible to separate the $\mathrm{CO}$ content in the middle troposphere from that in the Upper Troposphere Lower Stratosphere (UTLS), at approximately $200 \mathrm{hPa}$. Strictly speaking only retrievals made with the same a priori are directly comparable. However, the variability that is observed in the DOFS is comparable to that which has been observed for IASI by George et al. (2009).

\subsubsection{Errors}

The vertical profiles for the simulated retrieval errors together with the vertical profile of the a priori variability are displayed in Fig. 12. In both cases the dominant error at all altitudes is the smoothing error $\left(\boldsymbol{\epsilon}_{\text {smooth }}\right)$. The other main contributing error is the measurement error $\boldsymbol{\epsilon}_{\text {meas }}$, which contributes mainly below about $5 \mathrm{~km}$. In addition to these two errors there is also a forward model parameter error $\boldsymbol{\epsilon}_{\text {param }}$, which constitutes the errors in the parameters that are considered to be important in the retrieval but are not themselves retrieved; here this represents the errors in the trace gases that are absorbers in the spectral region (see Sect. 3.3.1), but are not retrieved. The forward model parameter error has been calculated by using linear approach for the error analysis, outlined by Rodgers (2000), with a specific covariance matrices for each of the non-retrieved trace gases. The square root of the diagonal elements $\mathbf{S}_{b}$ are determined from a set of one sigma profiles developed by Remedios et al. (2007), and the off-diagonal elements are calculated using the GaussMarkov equation (Eq. 10). The total random error $\boldsymbol{\epsilon}_{\text {ran }}$ is defined here as the total error from the measurement, smoothing and forward model parameter error terms. As could be
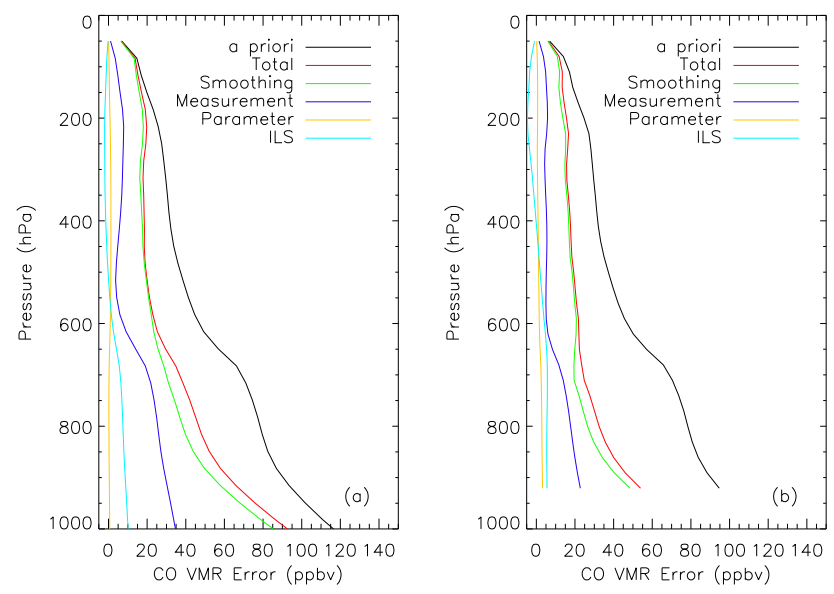

Fig. 12. Same as Fig. 11 for the ULIRS CO tropospheric error profiles. (a) Arctic Ocean and (b) Namibian Mountains.

anticipated from the information content analysis, and due to the fact that the smoothing error is dominant above all the other errors, the total error is higher for the Arctic Ocean simulated retrieval, than for that over the Namibian mountains. In general there is a large reduction in total error in comparison to the a priori variability: up to $59 \%$ over Namibia, and 47\% over the Arctic Ocean. However, the reduction of uncertainty about the $\mathrm{CO}$ vertical distribution is not significant above approximately $15 \mathrm{~km}$.

For each retrieval a total systematic error is also calculated $\left(\boldsymbol{\epsilon}_{\mathrm{sys}}\right)$. This is defined as the root mean square of three terms: the ILS error, the radiometric stability error, and the radiometric accuracy error. The IASI Science Plan (CamyPeyret and Eyre, 1998) states that the IASI instrument aims for a maximum error of $1 \%$ in the ILS, a relative error of $0.3 \mathrm{~K}$ at $280 \mathrm{~K}$ for the radiometric stability error (approximately $1.2 \%$ ), and a relative error of $0.2 \mathrm{~K}$ at $280 \mathrm{~K}$ for the radiometric accuracy error (approximately $0.8 \%$ ); and these values are used in the derivation of the systematic error for each retrieval. These errors are shown in Fig. 12.

\subsection{Sensitivity of the ULIRS}

The three main features that exemplify the ULIRS are now characterised, so as to give a good indication as to the sensitivity of the retrieval scheme to these three parameters, namely: surface elevation, surface emissivity, and a quantified solar component. This section aims to enumerate the differences that are introduced into the retrieved $\mathrm{CO}$ product by varying these parameters. It should be noted however, that even for a perfect retrieval scheme the retrieved state vector will not be equal to the true state vector, i.e. $\hat{\boldsymbol{x}} \neq \boldsymbol{x}_{\mathrm{t}}$. This is because of the smoothing that has been introduced by the limited resolution of the retrieval. As such, for a perfect retrieval (i.e. a retrieval for which there is no source of error, 


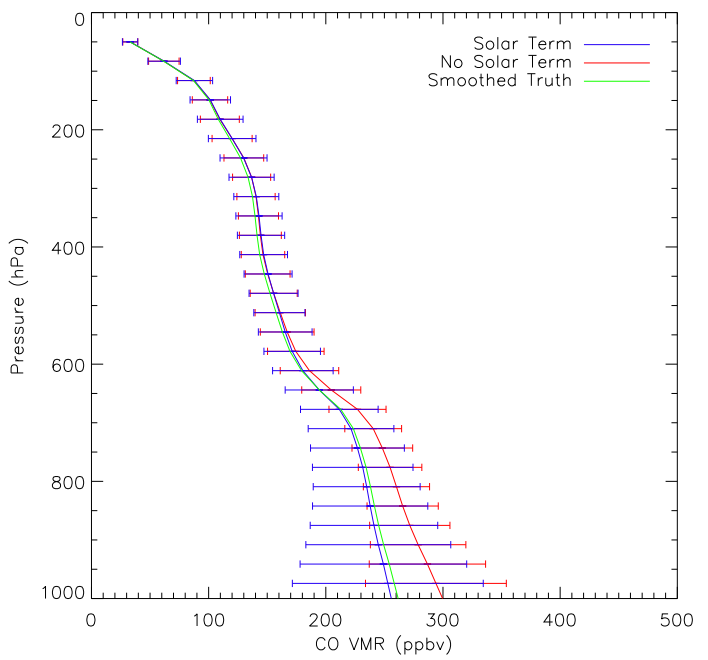

Fig. 13. The effect that the inclusion of solar reflected component has on the retrieved $\mathrm{CO}$ product. These retrievals were performed on radiances which were simulated under daytime mid-latitudinal atmospheric conditions, with a surface emissivity of 0.84 (representative of a desertified region), and a surface elevation of $0 \mathrm{~m}$. The total column densities for the retrieved product with and without a solar term are $5.48 \times 10^{18}$ molec $\mathrm{cm}^{-2}$ and $6.43 \times 10^{18}$ molec cm ${ }^{-2}$, respectively, compared to a value of $5.61 \times 10^{18}$ molec cm $^{-2}$ for the smoothed truth.

apart from that introduced by the discretising of the atmosphere), $\hat{\boldsymbol{x}}$ would be given as:

$\hat{\boldsymbol{x}}=\boldsymbol{x}_{\mathrm{a}}+\mathbf{A}\left(\boldsymbol{x}_{\mathrm{t}}-\boldsymbol{x}_{\mathrm{a}}\right) \neq \boldsymbol{x}_{\mathrm{t}}$.

As discussed in Sect. 3.1.1, the ULIRS includes a solar reflected component in its approximation of the forward function, and a quantification as to the effect that this inclusion has on the retrieved $\mathrm{CO}$ product is now demonstrated. Simulated radiances were produced using a solar reflected term, mid-latitudinal atmospheric conditions with an enhanced $\mathrm{CO}$ concentration, a surface emissivity of 0.84 , and a surface elevation of $0 \mathrm{~m}$; two different retrievals were then performed on these simulated radiances, one of which included a solar reflected component, and one which did not. As can be seen from Fig. 13, the effect of not including a solar term means that the retrieved profile deviates significantly from that of the smoothed truth, which represents the best possible retrieval. The total column densities for the retrieved product with and without a solar term are $5.48 \times 10^{18}$ molec $\mathrm{cm}^{-2}$ and $6.43 \times 10^{18}$ molec $\mathrm{cm}^{-2}$, respectively, compared to a value of $5.61 \times 10^{18} \mathrm{molec} \mathrm{cm}^{-2}$ for the smoothed truth. The effect of neglecting a surface solar reflected term is much more pronounced over a desertified region than a water mass, which can largely be explained by the difference in the albedos (see Eq. 2). As discussed in Sect. 3.1.1 the solar reflected component utilises the ACE solar spectra to account for the reflected solar flux in the TOA radiances. Figure 14 demonstrates that the differences between using this high resolution

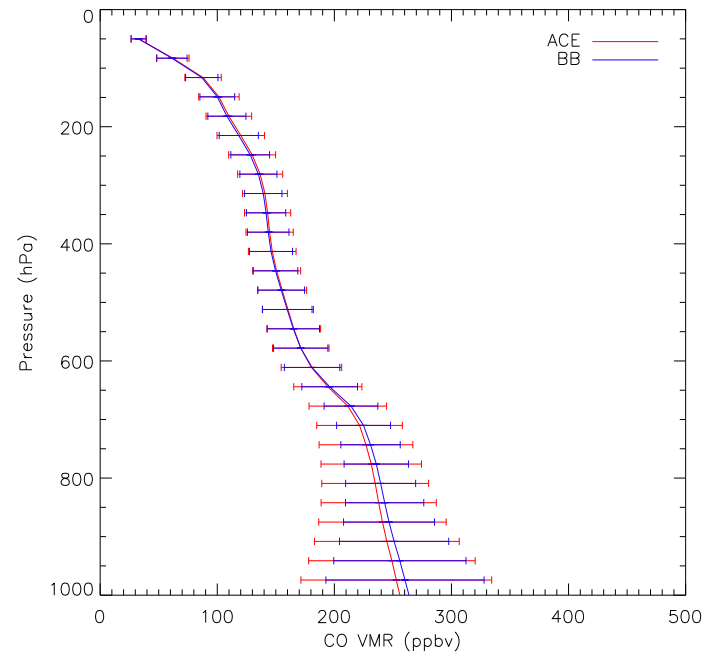

Fig. 14. The effect that the inclusion of a high resolution solar spectrum (ACE), in comparison to a simple blackbody radiance (BB), has on the retrieved $\mathrm{CO}$ product. These retrievals were performed on radiances which were simulated under daytime mid-latitudinal atmospheric conditions, with a surface emissivity of 0.84 (representative of a desertified region), and a surface elevation of $0 \mathrm{~m}$.

spectrum, and simply assuming a simple black body radiance are non-negligible, especially near the surface.

Another feature of the ULIRS is its use of a surface emissivity, selected for each IASI IFOV using both spectral and spatial parameters (see Sect. 3.4.1); a sensitivity test was performed so as to investigate the effect that surface emissivity had on the retrieved $\mathrm{CO}$ product. A set of radiances were simulated using mid-latitudinal atmospheric conditions with an enhanced $\mathrm{CO}$ concentration, a surface elevation of $0 \mathrm{~m}$, nighttime conditions (hence no solar reflected component), and a surface emissivity of 0.84 , chosen because it is representative of a desertified landscape in the CO TIR spectral window. Two separate retrievals were then performed using the ULIRS, identical in every respect apart from their assumed surface emissivities, which were chosen to be 0.84 , and 1.0. Figure 15 demonstrates the effect that an incorrect knowledge of the surface emissivity can have on the retrieved $\mathrm{CO}$ product. The total column densities are $5.76 \times 10^{18} \mathrm{molec}^{-2}$ for the case of an assumed surface emissivity of $1,5.52 \times 10^{18}$ molec cm $^{-2}$, for a surface emissivity of 0.84 , and $5.52 \times 10^{18}$ molec $\mathrm{cm}^{-2}$ for the smoothed truth (which used a surface emissivity of 0.84 ). The results of this sensitivity analysis demonstrate the importance of using a surface emissivity which is as representative of the truth as is possible, with the significance of an accurate surface emissivity further emphasised by the inclusion of a solar term (not shown).

Section 3.4.2 explained how the ULIRS incorporates a spatially well defined topographic map to ascertain the surface elevation for each IASI IFOV, and then how that 


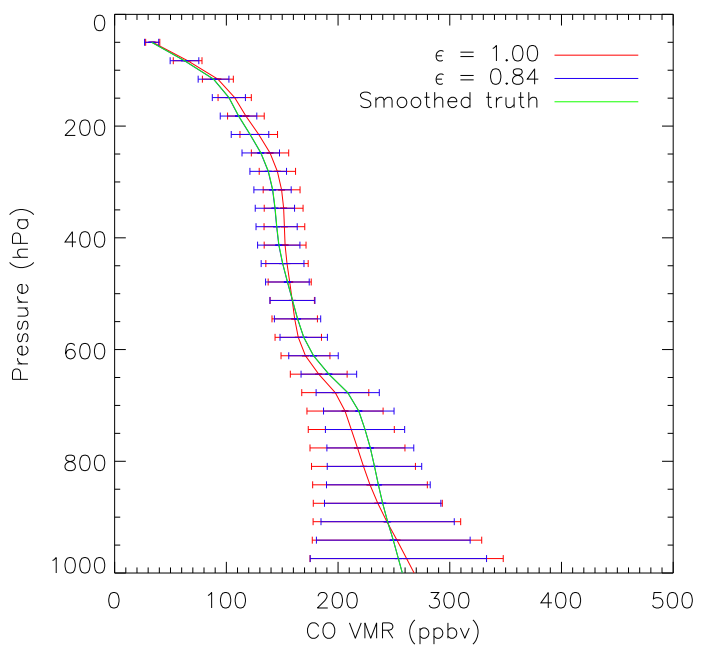

Fig. 15. The effect of surface emissivity on the retrieved CO product. These retrievals were performed on radiances which had been simulated using daytime mid-latitudinal atmospheric conditions, a surface emissivity of 0.84 , and a surface elevation of $0 \mathrm{~m}$. The total column densities are $5.76 \times 10^{18}$ molec $\mathrm{cm}^{-2}$ for the case of an assumed surface emissivity of $1,5.52 \times 10^{18} \mathrm{molec}^{-2}$, for an emissivity of 0.84 , and $5.52 \times 10^{18} \mathrm{molec}^{-2}$ for the smoothed truth (which assumed a surface emissivity of 0.84 ).

information is used to adjust the pressure levels for the retrieval. A sensitivity test was performed to quantify the effect that a poor representation of the topography of the retrieval scene can have on the retrieved $\mathrm{CO}$ product, the results of which are shown in Fig. 16. These retrievals were performed on radiances which were simulated using nighttime mid-latitudinal atmospheric conditions with an enhanced $\mathrm{CO}$ concentration, an emissivity of 0.98 , and a surface elevation of $1000 \mathrm{~m}$. The total column densities are $5.06 \times 10^{18} \mathrm{molec} \mathrm{cm}^{-2}$ for the case of an assumed surface elevation of $0 \mathrm{~m}, 4.39 \times 10^{18} \mathrm{molec} \mathrm{cm}^{-2}$, for an elevation of $1000 \mathrm{~m}$, and $4.39 \times 10^{18}$ molec $\mathrm{cm}^{-2}$ for the smoothed truth (which assumed a surface elevation of $1000 \mathrm{~m}$ ). These results highlight the importance of using a surface elevation which is as accurate a depiction of the true elevation of the IASI IFOV as possible.

A linear error analysis was performed to establish the error terms that are introduced by not accounting for the solar reflected component, surface emissivity, and topography of the scene, the results of which are shown in Fig. 17. This plot was generated from the different parameter errors, which were calculated using the following formula proposed by Rodgers (2000):

$\boldsymbol{\epsilon}=\mathbf{G}_{\mathrm{y}} \mathbf{K}_{b}(\hat{\boldsymbol{b}}-\boldsymbol{b})$

where $\boldsymbol{\epsilon}$ is the error associated with the parameter $\boldsymbol{b}, \mathbf{G}_{\mathrm{y}}$ is the gain matrix, and $\mathbf{K}_{b}$ is the Jacobian for each of the parameters. In order to quantify these error values, the same

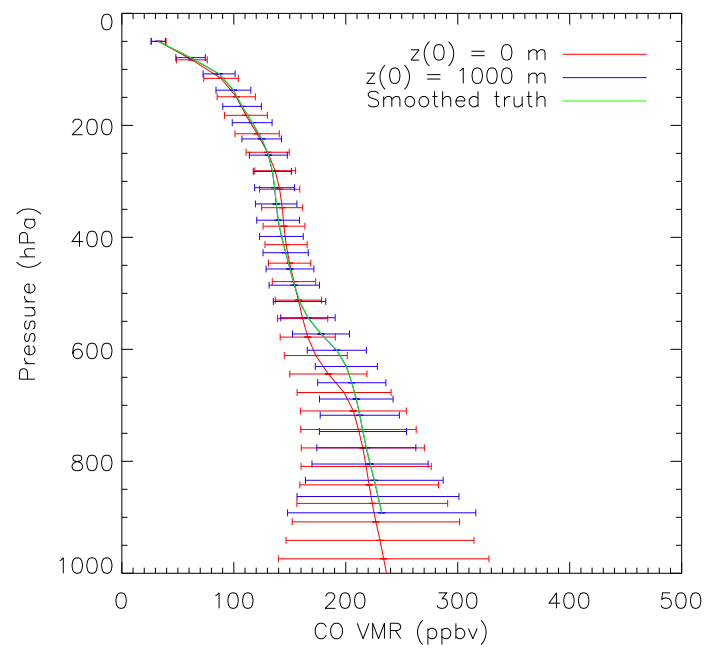

Fig. 16. The effect of surface elevation on the retrieved $\mathrm{CO}$ product. These retrievals were performed on radiances which had been simulated using nighttime mid-latitudinal atmospheric conditions, a surface emissivity of 0.98 , and a surface elevation of $1000 \mathrm{~m}$. The total column densities are $5.06 \times 10^{18}$ molec cm ${ }^{-2}$ for the case of an assumed surface elevation of $0 \mathrm{~m}, 4.39 \times 10^{18}$ molec cm $^{-2}$, for an elevation of $1000 \mathrm{~m}$, and $4.39 \times 10^{18}$ molec $\mathrm{cm}^{-2}$ for the smoothed truth (which assumed a surface elevation of $1000 \mathrm{~m}$ ).

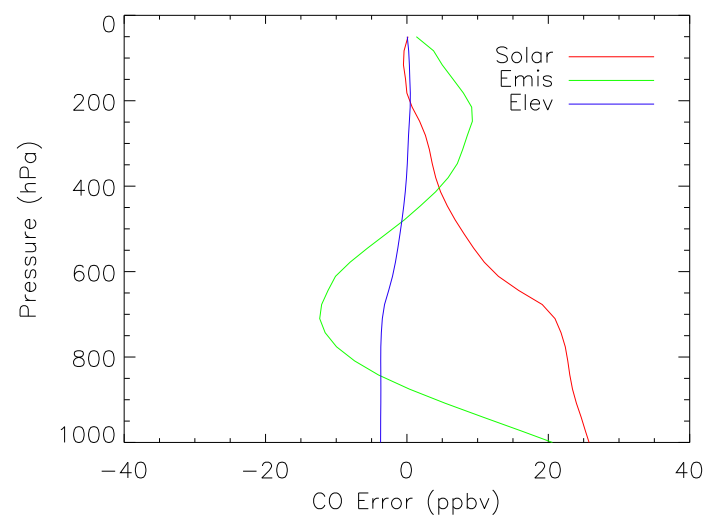

Fig. 17. The error terms introduced by not accounting for the solar reflected (red), surface emissivity (green) and surface topographic (blue) components. The errors have been calculated using a linear error analysis, as given in Rodgers (2000), using the same simulated retrievals that were used to generate Figs. 13-16.

simulated retrievals (with and without consideration of the appropriate parameters) that were used to produce Figs. 13 to 16 were run. As can be seen from Fig. 17, by not carefully considering the solar reflected term, surface emissivity, and topography of the retrieval scene, a significant errors are introduced into the retrieval. 


\subsubsection{Retrievals with IASI data}

To demonstrate the effects of real data, an area was chosen within the study region of Southern Africa in which land variations, emissivity, and solar reflection each played a part. 710 profiles were retrieved in nominally cloud free scenes over the Namibian coastline region for 26 August 2007, and Fig. 18 demonstrates the mean differences that are observed in real retrievals by either accounting for or not correctly taking into consideration the three aforementioned parameters. As can be seen from Fig. 18a, neglecting the solar reflected term has a very real and significant effect on the retrieved CO profiles. Figure $18 \mathrm{~b}$ shows that assuming a surface emissivity of 1 also introduces a significant effect on the retrieved CO profiles, and this effect is obviously pronounced over regions of low emissivity. As can be seen from Fig. 18c the surface topography is the most significant of the three parameters, in terms of the effect that it has on the retrieved product. This can in part be explained because of the crucial role that the pressure grid (see Sect. 3.2.2) has on the retrieved product, and whilst assuming a global surface elevation of $0 \mathrm{~m}$ is a significant simplification, the effect that such a simplification has on the retrieved product demonstrates why an accurate depiction of the topography is necessary. Over $99 \%$ of the retrieved profiles converged within 10 iterations, with the mean number of iterations between 3 and 4 .

Whilst every care has been taken to ensure that the solar reflected term, surface emissivity and topography of the scene have been correctly taken into account in the retrieval scheme, they cannot be known exactly, and as such will introduce a forward model parameter bias. These errors are considered separately from those earlier defined as $\boldsymbol{\epsilon}_{\text {param }}$, and in order to quantify them, it is necessary to perform a linear error analysis, as given by Eq. (12), using a representative uncertainty for each of the parameters under consideration. For the error in the solar reflected term $\boldsymbol{\epsilon}_{\mathrm{sol}}$ it was decided that the dominant error source would be in the assumption of the surface albedo, and thus the uncertainty for this term would come from that of the surface emissivity $\boldsymbol{\epsilon}_{\text {emis. }}$. An uncertainty of $5 \%$ is assigned to the surface emissivity (with the effect that this has on the surface albedo being applied to the solar reflected term), with an uncertainty of $7 \%$ being assigned to the topography of the scene. The uncertainty in the topography $\boldsymbol{\epsilon}_{\text {elev }}$ was derived by dividing the globe into $12 \mathrm{~km}$ "pseudo-IASI" pixels, and then calculating the standard deviation of surface height as a fraction of the value that was assigned to that pixel by the ULIRS for each scene. Once these values had been assigned, a detailed error budget for each retrieval could be calculated. Figure 19 shows these parameter errors for the retrieved scene shown in Fig. 12b, and as can be seen they are much smaller than the measurement and smoothing errors shown in Fig. 12b, but are not negligible and so must still be taken into account when calculating the total error, which is one of the outputs of the ULIRS product. A full ULIRS retrieval, using
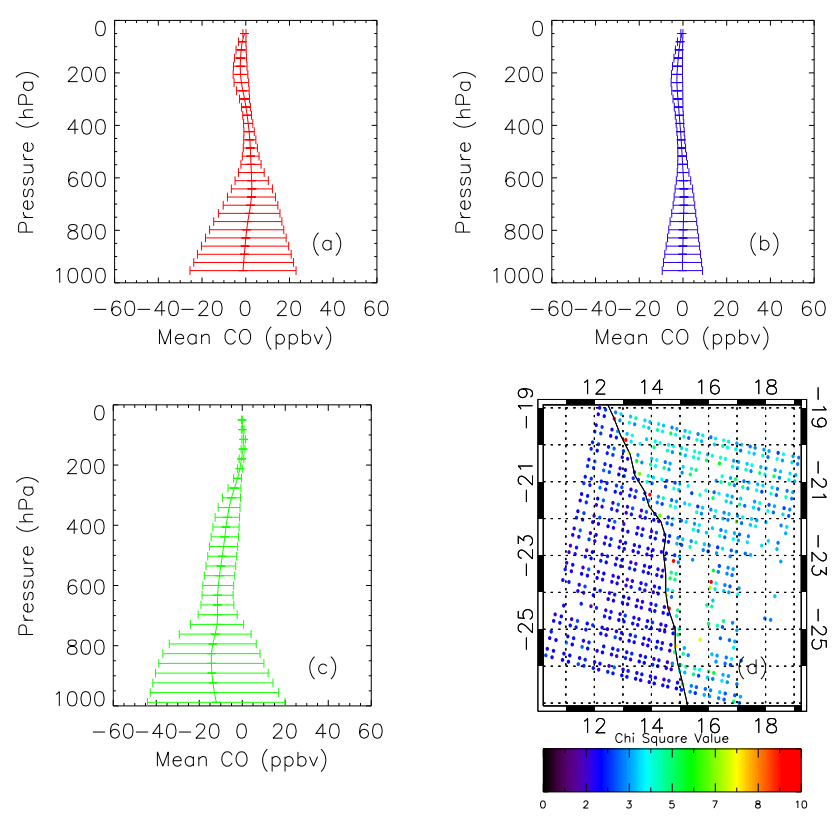

Fig. 18. The effect of different parameters on the retrieved CO profile: (a) the mean solar reflected term difference (retrieval with solar reflected term-retrieval without solar reflected term) in the CO profile, horizontal lines indicate the standard deviation; (b) the mean emissivity difference (retrieval with UW emissivity-retrieval with assumed emissivity of 1) in the CO profile, horizontal lines indicate the standard deviation; (c) the mean surface topography difference (retrieval with USGS topography-retrieval with assumed surface elevation of $0 \mathrm{~m}$ ) in the $\mathrm{CO}$ profile, horizontal lines indicate the standard deviation; (d) the region over which the mean differences and standard deviations have been calculated, also plotted is the chi squared value of the retrieval.

these associated error statistics, and for the region shown in Fig. 18d was performed, the results for which are tabulated in Table 1, where $\boldsymbol{\epsilon}_{\text {ran }}$ is now defined as the total error from $\boldsymbol{\epsilon}_{\text {smooth }}, \boldsymbol{\epsilon}_{\text {meas }}, \boldsymbol{\epsilon}_{\text {param }}, \boldsymbol{\epsilon}_{\text {emis }}, \boldsymbol{\epsilon}_{\text {sol }}$, and $\boldsymbol{\epsilon}_{\text {elev }}$. From Table 1 the total errors in the total column were found to range from 18 to $34 \%$ of the retrieved total column density, with the random errors contributing the largest proportion of that, ranging from 16 to $33 \%$ of the retrieved values, however it should be noted that these errors also include a smoothing term; which is by far the most dominant error.

\section{Retrieval simulations for varying geographical regions}

In order to test the suitability of the ULIRS for retrieving tropospheric CO profiles and columns from IASI measured radiances, a series of simulations were performed. These involved using the RFM to simulate spectra for a variety of scenarios, and then analysing the differences between the retrieved state vector $\boldsymbol{x}$, and the smoothed true state vector, as given by Eq. (11). 
Table 1. Mean and one sigma standard deviations of the retrieved CO product and associated a priori and error terms. These statistics have been produced using a full ULIRS retrieval over the region illustrated in Fig. 18d, and correspond to the profile values at $500 \mathrm{hPa}$ and $200 \mathrm{hPa}$, as well as a total column density (TC). The terms used in the table are as follows: $\hat{\boldsymbol{x}}$, retrieved value; $\boldsymbol{x}_{\mathrm{a}}$, a priori value; $\boldsymbol{\epsilon}_{\mathrm{sys}}$, total systematic

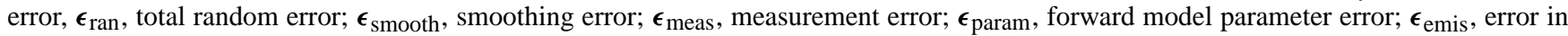
the surface emissivity; $\boldsymbol{\epsilon}_{\mathrm{sol}}$, error in the solar reflected term; $\boldsymbol{\epsilon}_{\mathrm{elev}}$, error in the surface topography.

\begin{tabular}{|c|c|c|c|c|c|c|c|c|c|c|c|}
\hline & $\hat{\boldsymbol{x}}$ & $x_{\mathrm{a}}$ & $\epsilon_{\mathrm{a}}$ & $\boldsymbol{\epsilon}_{\text {sys }}$ & $\epsilon_{\mathrm{ran}}$ & $\boldsymbol{\epsilon}_{\text {smooth }}$ & $\boldsymbol{\epsilon}_{\text {meas }}$ & $\boldsymbol{\epsilon}_{\text {param }}$ & $\boldsymbol{\epsilon}_{\mathrm{emis}}$ & $\boldsymbol{\epsilon}_{\mathrm{sol}}$ & $\boldsymbol{\epsilon}_{\mathrm{elev}}$ \\
\hline \multicolumn{12}{|l|}{$500 \mathrm{hPa}^{\mathrm{a}}$} \\
\hline Mean & 104.69 & 118.12 & 38.30 & 3.51 & 21.53 & 19.26 & 7.33 & 2.69 & 1.57 & 3.63 & 0.18 \\
\hline Sigma & 29.11 & 2.48 & 3.07 & 1.31 & 3.67 & 2.13 & 3.21 & 0.98 & 1.05 & 2.96 & 0.15 \\
\hline \multicolumn{12}{|l|}{$200 \mathrm{hPa}^{\mathrm{a}}$} \\
\hline Mean & 78.34 & 99.90 & 24.72 & 4.13 & 16.10 & 14.31 & 6.54 & 0.80 & 1.81 & 1.16 & 0.34 \\
\hline Sigma & 23.74 & 1.94 & 1.15 & 1.64 & 1.08 & 1.07 & 0.49 & 0.32 & 0.97 & 1.32 & 0.35 \\
\hline \multicolumn{12}{|l|}{$\mathrm{TC}^{\mathrm{b}}$} \\
\hline Mean & 2.33 & 2.41 & 0.90 & 0.15 & 0.56 & 0.45 & 0.22 & 0.07 & 0.05 & 0.14 & 0.01 \\
\hline Sigma & 0.59 & 0.29 & 0.16 & 0.04 & 0.22 & 0.17 & 0.08 & 0.05 & 0.05 & 0.15 & 0.01 \\
\hline
\end{tabular}

a units of ppbv

$\mathrm{b}$ units of $10 \times 10^{18} \mathrm{Molec}^{-2}$

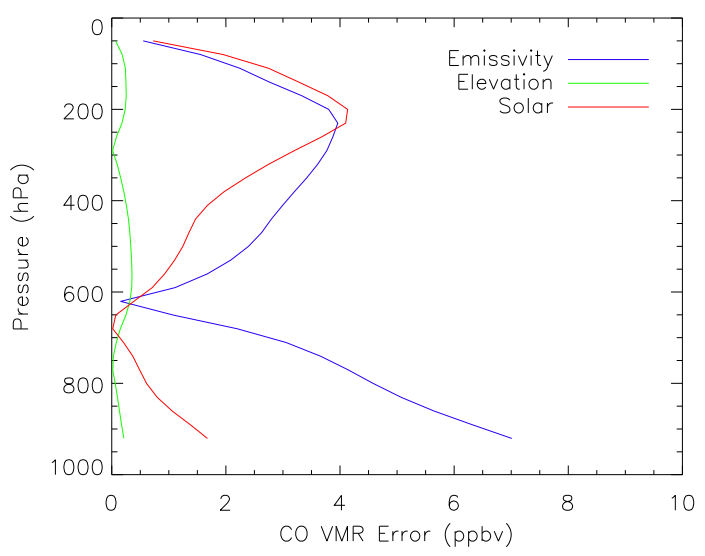

Fig. 19. An error budget, as in Fig. 12b, but showing the error associated with the surface emissivity (blue), solar reflected term (red), and scene topography (green).

A set of $\mathrm{CO}$, water vapour and temperature profiles were provided by the CAMELOT (Chemistry of the Atmosphere Mission concEpts and sentineL Observations Techniques) study (Levelt et al., 2009), which were produced using the TM3 CTM model (Heimann and Körner, 2003). There were 16 different atmospheric schemes used in the CAMELOT study, ranging from a Siberian permafrost to a polluted $\mathrm{Pa}$ cific region, and the scenarios which were chosen for testing the ULIRS were those which corresponded to a tropical background region, a tropical BioMass Burning (BMB) over a landmass, a tropical BMB over the ocean, and a subtropical background region. These scenarios were chosen so as to best test the ULIRS' ability to accurately retrieve CO products over the African region, so as to be consistent with the rest of this study.
Different atmospheric spectra were simulated using the RFM and the CAMELOT derived profiles, with a realistic random noise component (ranging between $\pm 2 \mathrm{nW} \mathrm{cm}^{-2} \mathrm{~cm}^{-2} \mathrm{sr}^{-1}$ ). From these simulated spectra the ULIRS attempted to retrieve the true $\mathrm{CO}$ profile, as given by the CAMELOT profiles, for a variety of scenarios. For each scenario the retrieval process was repeated a number of times, so as to account for the random noise component that was added to the simulated spectra and profiles, with a mean ideal profile and a mean retrieved profile then being compared. The DOFS for the retrievals ranged between 1 and 2 , indicating that the retrieved $\mathrm{CO}$ product provides 1 to 2 pieces of information on the vertical profile. One may thus expect good information on some vertically weighted column but not on gradients. Applying the $\mathbf{A}$ of the retrieved product to the true CAMELOT profile, via Eq. (11) produces a profile that is what IASI would see if its capability were as advertised by the error analysis that led to the construction of A.

The first set of simulations that were carried out involved the retrieval of a set of $\mathrm{CO}$ profiles, providing that the water vapour and temperature profiles were well represented by the a priori information. As can be seen from Fig. 20, for all of the different CAMELOT scenarios which were retrieved, the difference between the ideal smoothed profile (given by Eq. 11) and the retrieved profile is very small, and certainly the two profiles always agree to within the a posterior error. The ideal and retrieved profiles have similar vertical gradients but this merely reflects the a priori information. More instructive is that for all of the scenarios the total CO columns are similar, with less than a $1 \%$ bias for IASI in all cases. It is also important to note that there has been a significant (up to $60 \%$ ) reduction in the error, as is evident by comparing 

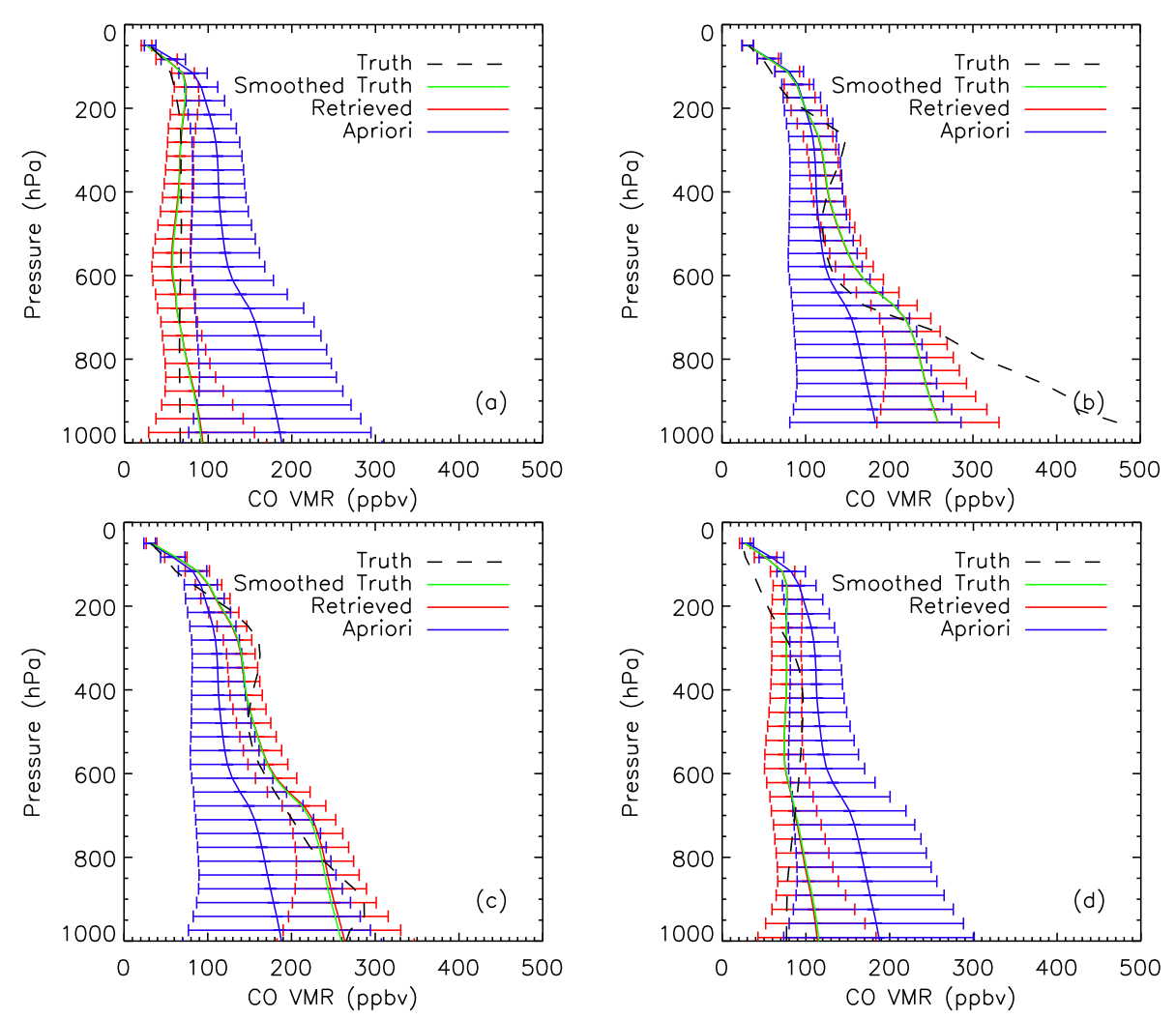

Fig. 20. Retrieved CAMELOT profiles for a variety of scenarios, in which the a priori water vapour and temperature are well known (i.e. equal to those given by the CAMELOT profiles), the surface elevation is $0 \mathrm{~m}$, and the surface emissivity is 0.98 . In each plot there is the a priori profile used by the ULIRS with associated error bars, the ULIRS retrieved profile with associated error bars, the true CAMELOT profile, and the smoothed CAMELOT profile. The smoothed profile is calculated using Eq. (11), and represents the best possible profile that can be retrieved by ULIRS, in the absence of any error. The different CAMELOT scenarios and the amount by which the tropospheric CO columns (retrieved-smoothed truth) differ by are given as: (a) tropical background region, 0.11\%; (b) tropical BMB over land, $-0.09 \%$; (c) tropical BMB over ocean $0.68 \%$; and (d) subtropical background region $-0.70 \%$.

the a priori to the a posterior error bars. The large error reduction at the surface is a reasonably surprising result, as the IASI instrument is not particularly sensitive to the surface, as can be seen from Fig. 11. This reduction in error reduction is most likely due to the information projection effect discussed by Deeter et al. (2010). The correlation length of the a priori covariance matrix effectively determines the vertical influence for a change in the concentration of $\mathrm{CO}$ at a specific pressure level. This means that for large correlation lengths, retrievals at pressure levels that are insensitive to $\mathrm{CO}$ can be strongly influenced by more sensitive levels. One example of where this "false influence" can occur is for scenes with a low-thermal contrast, and hence a lack of sensitivity to the surface; in such scenes a large correlation length can result in the projection of $\mathrm{CO}$ features from the mid-troposphere, where there is an increased sensitivity, to the surface. As the ULIRS uses a constant a priori covariance matrix for $\mathrm{CO}$, which has a smoothing length of approximately $400 \mathrm{hPa}$ (estimated by computing the delta-pressure for which the offdiagonal element of the covariance matrix was found to be
$1 / e^{2}$ times the corresponding diagonal element), it is more prone to being influenced by mid-tropospheric $\mathrm{CO}$ events, to which it has a greater sensitivity compared to the surface.

Following the simulation where the true water vapour and temperature profiles were well represented by the a priori, retrievals were performed where either the a priori water vapour or temperature profiles were up to $5 \%$ different from the truth, across the whole profile, in these situations (not shown) the ULIRS still produced retrievals with less than a $3 \%$ bias. Even in the case where the a priori water vapour and temperature profiles, as well as the surface temperature were significantly different from the truth, the ULIRS was able to retrieve a very good approximation of the true $\mathrm{CO}$ profile, as is demonstrated in Fig. 21, with the bias in IASI being less than $2 \%$ for every simulation. In addition to this the difference between the retrieved total column and the true total column (not shown) is less than $10 \%$ for every CAMELOT scenario, even in the case when both the a priori water vapour and temperature represent a wide departure from the truth. 

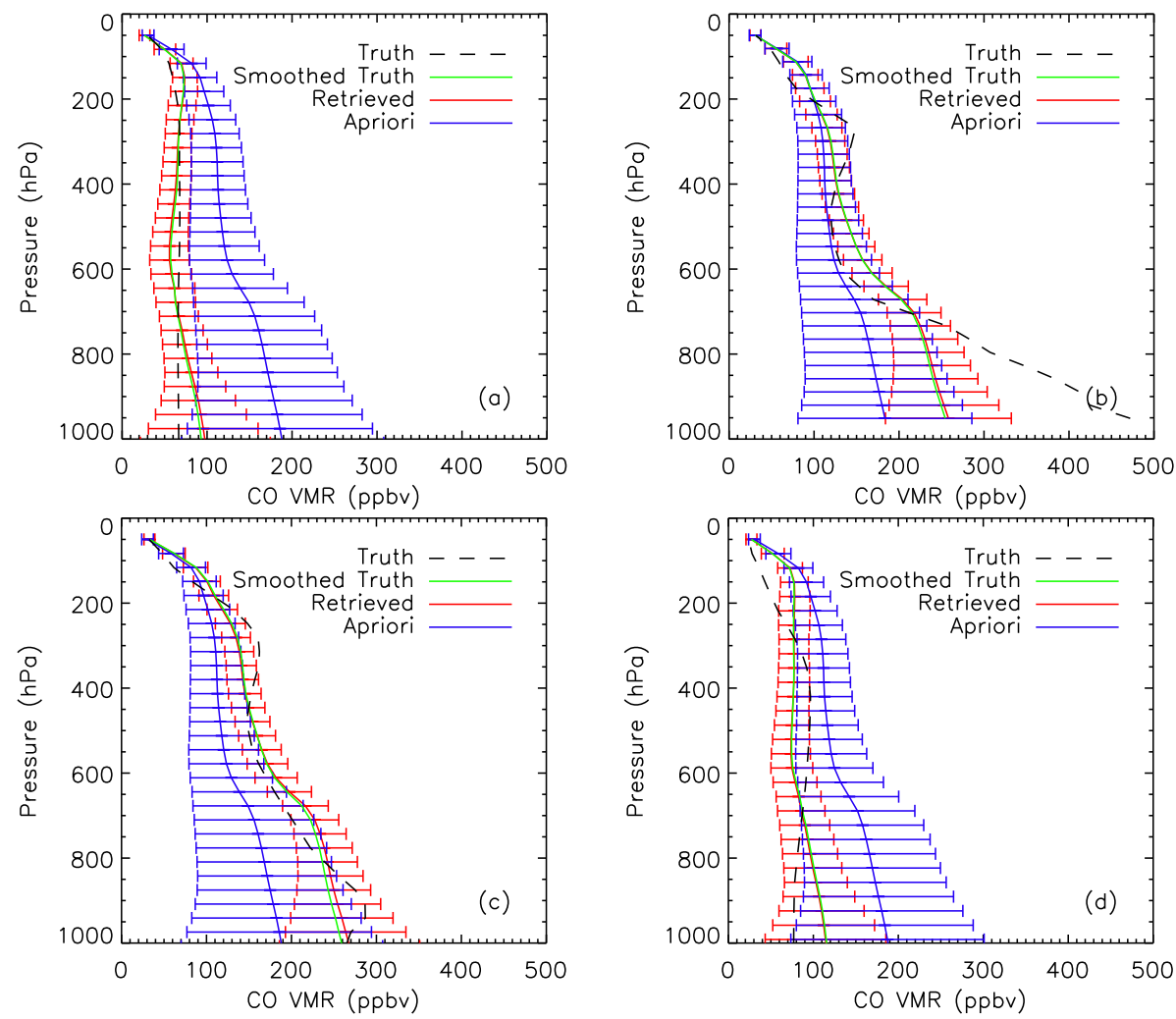

Fig. 21. Retrieved CAMELOT profiles, as for Fig. 20, but with the a priori surface temperature, water vapour and temperature profiles differing from the truth by a $\pm 5 \%$ random error at each of the retrieval pressure levels. The tropospheric CO columns differ (retrieved-truth) by: (a) $-0.75 \%$; (b) $-0.46 \%$; (c) $1.16 \%$; and (d) $-0.55 \%$.

It should also be noted that whilst Figs. 20 and 21 indicate that the retrieved profile is able to move significantly far from the a priori, this has not yet been tested for a scenario in which there are very low atmospheric $\mathrm{CO}$ concentrations. Given that the $\mathrm{CO}$ a priori profile has been constructed using a set of profiles that do not include any very low $\mathrm{CO}$ concentrations, there is a possibility that that this may result in a positive bias. This is especially likely to be so over Ocean scenes with low background concentrations of $\mathrm{CO}$. However, the results of Figs. 20 and 21, also show that the retrieved profile is able to move significantly from the a priori.

\section{Conclusions}

This paper has described in detail the University of Leicester IASI retrieval Scheme (ULIRS), a retrieval scheme that has been developed to retrieve tropospheric CO profiles and total column densities, using IASI TOA measured radiances. This retrieval scheme is an improvement on other retrieval schemes (see e.g., Turquety et al., 2009; EUMETSAT, 2009), in that it uses a spatially, spectrally, and temporally dependant emissivity for each retrieval scene. It also uses a DEM with a resolution of $30^{\prime \prime}$, thus enabling a very accurate representation of the topographic homogeneity of the IASI IFOV, and also takes into account the effect of backscattered solar radiation, incorporating a solar spectrum derived using the ACE-FTS instrument. Whilst the residuals from the retrieval indicate that the modelling of the solar term is correct, we accept that further studies exploring the accuracy of solar representation would be desirable.

The retrieval and characterisation algorithms that have been developed have been described in detail, and a thorough characterisation of the retrievals has shown that the high quality radiances measured by the IASI instrument, which combines a high signal to noise ratio and a high spectral resolution, enable the retrieval of a tropospheric $\mathrm{CO}$ product. This product consists of a CO total column, as well as up to 2 pieces of information about the $\mathrm{CO}$ vertical profiles. The first piece of information is in the lower-middle troposphere at approximately $500 \mathrm{hPa}$ and the second one is in the UTLS, at approximately $200 \mathrm{hPa}$. A detailed error analysis showed that the main source of error is the smoothing error, with an added contribution from the measurement error in the lowermiddle troposphere. It has been shown that the retrieved profiles represent a reduction in error, when compared to the a priori variability, of up to $60 \%$. As well as providing a set of $\mathrm{CO}$ profiles and total column amounts, the ULIRS also 
delivers matching a priori and averaging kernels, as well as a detailed error budget, so that the data can be correctly interpreted, and if needs be compared with another product. The total errors (including a smoothing term) in the total column were found to range from 18 to $34 \%$ of the retrieved total column density, with the random errors contributing the largest proportion of that, ranging from 16 to $33 \%$ of the retrieved values. It should be noted that because of the selection process for the a priori in this particular study, retrievals over a low oceanic background source a re expected to be positively biased, however the flexibility of the ULIRS means that a different a priori could be chosen for this or any other particular region.

Full retrieval simulations have demonstrated that even when the a priori represents a significant departure from the truth, the ULIRS is able to retrieve a CO total column which differs from the idealised true total column by less than $3 \%$. The next step in the validation of the retrieval algorithm will be to compare ULIRS retrievals with those of in situ measurements, such as those made by aircraft or ground sampling sites, and to carry out an intercomparison between the ULIRS derived CO product and that from other space-borne instruments.

Whilst the ULIRS was never designed to retrieve at operational speeds (or near real time), the computational efficiency of the scheme could certainly be improved, so that localised regions spanning a wide temporal range could be retrieved more rapidly. The main limitation to this improvement in retrieval speed comes from the current choice of forward model, as the RFM is unable to use appropriate approximations and pre-computed Look-Up Tables (LUTs) for the ULIRS' choice of retrieval parameters. This is a further indication that the investigation of a possible replacement for the RFM would be a worthwhile study. One possible candidate is the Radiative Transfer Model for TOVS (RTTOV) (Saunders et al., 1999), which expresses the transmittances of atmospheric gases as a function of profile dependent predictors, and which is very computationally efficient. Eventually the ULIRS should be modified so as to allow the user to select from a variety of forward models, should they so wish.

Acknowledgements. IASI has been developed and built under the responsibility of the Centre National d'Etudes Spatiales (CNES, France). It is flown onboard the MetOp satellites as part of the EUMETSAT Polar System. The IASI L1 data are received through the EUMETCast near real time data distribution service.

The authors would like to thank Peter Bernath for the use of ACE solar spectra, Nigel Richards and Martyn Chipperfield for TOMCAT data, NEODC for access to ECMWF data, the NERC for funding S. M. Illingworth, and EUMETSAT for access to the IASI data. SATSCAN-IR is a project selected by EUMETSAT/ESA under the first EPS/Metop RAO.

Edited by: U. Friess

\section{References}

Barret, B., Turquety, S., Hurtmans, D., Clerbaux, C., Hadji-Lazaro, J., Bey, I., Auvray, M., and Coheur, P.-F.: Global carbon monoxide vertical distributions from spaceborne high-resolution FTIR nadir measurements, Atmos. Chem. Phys., 5, 2901-2914, doi:10.5194/acp-5-2901-2005, 2005.

Blumstein, D., Chalon, G., Carlier, T., Buil, C., Hébert, P., Maciaszek, T., Ponce, G., Phulpin, T., Tournier, B., Siméoni, D., Astruc, P., Clauss, A., Kayal, G., and Jegou, R.: IASI instrument: Technical overview and measured performances, in: Society of Photo-Optical Instrumentation Engineers (SPIE) Conference Series, edited by: Strojnik, M., vol. 5543, 2004.

Bovensmann, H., Burrows, J. P., Buchwitz, M., Frerick, J., Noël, S., Rozanov, V. V., Chance, K. V., and Goede, A. P. H.: SCIAMACHY: Mission objectives and measurement modes, J. Atmos. Sci., 56, 127-150, 1999.

Camy-Peyret, C. and Eyre, J.: IASI Science Plan, Tech. rep., ISSWG, 1998.

Ceccherini, S. and Ridolfi, M.: Technical Note: Variancecovariance matrix and averaging kernels for the LevenbergMarquardt solution of the retrieval of atmospheric vertical profiles, Atmos. Chem. Phys., 10, 3131-3139, doi:10.5194/acp-103131-2010, 2010.

Chipperfield, M. P.: New version of the TOMCAT/SLIMCAT offline chemical transport model: Intercomparison of stratospheric tracer experiments, Q. J. Roy. Meteorol. Soc., 132, 1179-1203, 2006.

Clerbaux, C., Boynard, A., Clarisse, L., George, M., Hadji-Lazaro, J., Herbin, H., Hurtmans, D., Pommier, M., Razavi, A., Turquety, S., Wespes, C., and Coheur, P.-F.: Monitoring of atmospheric composition using the thermal infrared IASI/MetOp sounder, Atmos. Chem. Phys., 9, 6041-6054, doi:10.5194/acp-9-6041-2009, 2009.

Deeter, M., Edwards, D., Gille, J., Emmons, L., Francis, G., Ho, S.-P., Mao, D., Masters, D., Worden, H., and Drummond, J.: The MOPITT Version 4 CO Product: Algorithm Enhancements, Validation, and Long-Term Stability, J. Geophys. Res.-Atmos., 115, D07306, doi:10.1029/2009JD013005, 2010.

Deeter, M. N., Emmons, L. K., Francis, G. L., Edwards, D. P., Gille, J. C., Warner, J. X., Khattatov, B., Ziskin, D., Lamarque, J. ., Ho, S. ., Yudin, V., Attié, J.-L., Packman, D., Chen, J., Mao, D., and Drummond, J. R.: Operational carbon monoxide retrieval algorithm and selected results for the MOPITT instrument, J. Geophys. Res.-Atmos., 108, ACH1-1-ACH-1-11, 2003.

Deeter, M. N., Edwards, D. P., Gille, J. C., and Drummond, J. R.: Sensitivity of MOPITT observations to carbon monoxide in the lower troposphere, J. Geophys. Res.-Atmos, 112, D24306, doi:10.1029/2007JD008929, 2007.

Deeter, M. N., Edwards, D. P., Gille, J. C., and Drummond, J. R.: CO retrievals based on MOPITT near-infrared observations, J. Geophys. Res.-Atmos., 114, 4303-4311, 2009.

Dudhia, A.: Michelson Interferometer for Passive Atmospheric Sounding (MIPAS) Reference Forward Model (RFM), Software User's Manual, 2000.

Edwards, D. P.: GENLN2: A general line-by-line atmospheric transmittance and radiance model, NCAR Tech.Note, NCAR/TN-367+STR, 1992. 
EUMETSAT: Carbon Monoxide Retrieval Within the Operational IASI Level 2 Processor, Training and Validation Results, 2009.

Fortems-Cheiney, A., Chevallier, F., Pison, I., Bousquet, P., Carouge, C., Clerbaux, C., Coheur, P.-F., George, M., Hurtmans, D., and Szopa, S.: On the capability of IASI measurements to inform about CO surface emissions, Atmos. Chem. Phys., 9, 87358743, doi:10.5194/acp-9-8735-2009, 2009.

George, M., Clerbaux, C., Hurtmans, D., Turquety, S., Coheur, P.F., Pommier, M., Hadji-Lazaro, J., Edwards, D. P., Worden, H., Luo, M., Rinsland, C., and McMillan, W.: Carbon monoxide distributions from the IASI/METOP mission: evaluation with other space-borne remote sensors, Atmos. Chem. Phys., 9, 8317-8330, doi:10.5194/acp-9-8317-2009, 2009.

Hadji-Lazaro, J., Clerbaux, C., Couvert, P., Chazette, P., and Boonne, C.: Cloud filter for CO retrieval from IMG infrared spectra using ECMWF temperatures and POLDER cloud data, Geophys. Res. Lett., 28, 2397-2400, 2001.

Hase, F., Wallace, L., McLeod, S. D., Harrison, J., and Bernath, P.: The ACE-FTS atlas of the infared solar spectrum, J. Quant. Spectrosc. Ra., 111, 521-528, 2010.

Heimann, M. and Körner, S.: The Global Atmospheric Tracer Model TM3, Model Description and Users Manual Release 3.8a, Max Planck Institute for Biogeochemistry, MPIBGC, Jena, Germany, 2003.

Holloway, T., Levy II, H., and Kasibhatla, P.: Global distribution of carbon monoxide, J. Geophys. Res., 105, 12123-12147, 2000.

Illingworth, S. M., Remedios, J. J., and Parker, R. J.: Intercomparison of integrated IASI and AATSR calibrated radiances at 11 and $12 \mu \mathrm{m}$, Atmos. Chem. Phys., 9, 6677-6683, doi:10.5194/acp-96677-2009, 2009.

Justice, C. O., Vermote, E., Townshend, J. R. G., Defries, R., Roy, D. P., Hall, D. K., Salomonson, V. V., Privette, J. L., Riggs, G., Strahler, A., Lucht, W., Myneni, R. B., Knyazikhin, Y., Running, S. W., Nemani, R. R., Wan, Z., Huete, A. R., Van Leeuwen, W., Wolfe, R. E., Giglio, L., Muller, J., Lewis, P., and Barnsley, M. J.: The moderate resolution imaging spectroradiometer (MODIS): Land remote sensing for global change research, IEEE T. Geosci. Remote, 36, 1228-1249, 1998.

Kobayashi, H., Shimota, A., Kondo, K., Okumura, E., Kameda, Y., Shimoda, H., and Ogawa, T.: Development and evaluation of the interferometric monitor for greenhouse gases: A highthroughput Fourier-transform infrared radiometer for nadir Earth observation, Appl. Optics, 38, 6801-6807, 1999.

Larar, A. M., Smith, W. L., Zhou, D. K., Liu, X., Revercomb, H., Taylor, J. P., Newman, S. M., and Schlüssel, P.: IASI spectral radiance validation inter-comparisons: case study assessment from the JAIVEx field campaign, Atmos. Chem. Phys., 10, 411-430, doi:10.5194/acp-10-411-2010, 2010.

Levelt, P., Veefkind, J., Kerridge, B., Siddans, R., de Leeuw, G., Remedios, J., and Coheur, P.: CAMELOT Final Report, Issue 1, Tech. rep., ESA, 2009.

Logan, J. A., Prather, M. J., Wofsy, S. C., and McElroy, M. B.: Tropospheric chemistry: a global perspective, J. Geophys. Res., 86, 7210-7254, 1981.

McMillan, W. W., Barnet, C., Strow, L., Chahine, M. T., McCourt, M. L., Warner, J. X., Novelli, P. C., Korontzi, S., Maddy, E. S., and Datta, S.: Daily global maps of carbon monoxide from NASA's Atmospheric Infrared Sounder, Geophys. Res. Lett., 32, $1-4,2005$.
Reichle Jr., H. G., Anderson, B. E., Connors, V. S., Denkins, T. C., Forbes, D. A., Gormsen, B. B., Langenfelds, R. L., Neil, D. O., Nolf, S. R., Novelli, P. C., Pougatchev, N. S., Roell, M. M., and Steele, L. P.: Space shuttle based global CO measurements during April and October 1994, MAPS instrument, data reduction, and data validation, J. Geophys. Res.-Atmos., 104, $21443-$ 21454, 1999.

Remedios, J. J., Leigh, R. J., Waterfall, A. M., Moore, D. P., Sembhi, H., Parkes, I., Greenhough, J., Chipperfield, M. P., and Hauglustaine, D.: MIPAS reference atmospheres and comparisons to V4.61/V4.62 MIPAS level 2 geophysical data sets, Atmos. Chem. Phys. Discuss., 7, 9973-10017, doi:10.5194/acpd7-9973-2007, 2007.

Rinsland, C. P., Luo, M., Logan, J. A., Beer, R., Worden, H., Rider, D., Osterman, G., Gunson, M., Eldering, A., Goldman, A., Shephard, M., Clough, S. A., Rodgers, C., Lampel, M., and Chiou, L.: Nadir measurements of carbon monoxide distributions by the Tropospheric Emission Spectrometer instrument onboard the Aura Spacecraft: Overview of analysis approach and examples of initial results, Geophys. Res. Lett., 33, L22806, doi:10.1029/2006GL027000, 2006.

Rodgers, C.: Inverse Methods for Atmospheric Sounding: Theory and Practice, World Scientific Publishing Company, Singapore, 2000.

Rothman, L. S., Gordon, I. E., Barbe, A., Benner, D. C., Bernath, P. F., Birk, M., Boudon, V., Brown, L. R., Campargue, A., Champion, J., Chance, K., Coudert, L. H., Dana, V., Devi, V. M., Fally, S., Flaud, J., Gamache, R. R., Goldman, A., Jacquemart, D., Kleiner, I., Lacome, N., Lafferty, W. J., Mandin, J., Massie, S. T., Mikhailenko, S. N., Miller, C. E., Moazzen-Ahmadi, N., Naumenko, O. V., Nikitin, A. V., Orphal, J., Perevalov, V. I., Perrin, A., Predoi-Cross, A., Rinsland, C. P., Rotger, M., Šimečkova, M., Smith, M. A. H., Sung, K., Tashkun, S. A., Tennyson, J., Toth, R. A., Vandaele, A. C., and Vander Auwera, J.: The HITRAN 2008 molecular spectroscopic database, J. Quant. Spectrosc. Ra., 110, 533-572, 2009.

Saunders, R., Matricardi, M., and Brunel, P.: An improved fast radiative transfer model forassimilation of satellite radiance observations, Q. J. Roy. Meteorol. Soc., 144, 1547-1558, 1999.

Seemann, S. W., Borbas, E. E., Knuteson, R. O., Stephenson, G. R., and Huang, H.: Development of a global infrared land surface emissivity database for application to clear sky sounding retrievals from multispectral satellite radiance measurements, J. Appl. Meteorol. Clim., 47, 108-123, 2008.

Strabala, K. I., Ackerman, S. A., and Menzel, W. P.: Cloud properties inferred from 8-12- $\mu$ m data, J. Appl. Meteorol., 33, 212229, 1994.

Straume, A. G., Schrijver, H., Gloudemans, A. M. S., Houweling, S., Aben, I., Maurellis, A. N., De Laat, A. T. J., Kleipool, Q., Lichtenberg, G., Van Hees, R., Meirink, J. F., and Krol, M.: The global variation of $\mathrm{CH} 4$ and $\mathrm{CO}$ as seen by SCIAMACHY, Adv. Space Res., 36, 821-827, 2005.

Taylor, J. A., Zimmerman, P. R., and Erickson, D. J.: A 3-D modelling study of the sources and sinks of atmospheric carbon monoxide, Ecol. Modell., 88, 53-71, 1996.

Thompson, A. M.: The oxidizing capacity of the earth's atmosphere: Probable past and future changes, Science, 256, 1157$1165,1992$. 
Turquety, S., Hurtmans, D., Hadji-Lazaro, J., Coheur, P.-F., Clerbaux, C., Josset, D., and Tsamalis, C.: Tracking the emission and transport of pollution from wildfires using the IASI CO retrievals: analysis of the summer 2007 Greek fires, Atmos. Chem. Phys., 9, 4897-4913, doi:10.5194/acp-9-4897-2009, 2009. 